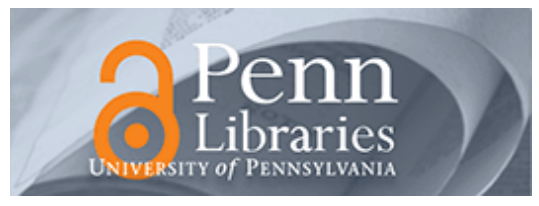

University of Pennsylvania

ScholarlyCommons

Finance Papers

Wharton Faculty Research

8-2014

\title{
Presidential Address: Investment Noise and Trends
}

Robert F. Stambaugh

University of Pennsylvania

Follow this and additional works at: https://repository.upenn.edu/fnce_papers

Part of the Finance Commons, and the Finance and Financial Management Commons

Recommended Citation

Stambaugh, R. F. (2014). Presidential Address: Investment Noise and Trends. The Journal of Finance, 69 (4), 1415-1453. http://dx.doi.org/10.1111/jofi.12174

This paper is posted at ScholarlyCommons. https://repository.upenn.edu/fnce_papers/284

For more information, please contact repository@pobox.upenn.edu. 


\title{
Presidential Address: Investment Noise and Trends
}

\begin{abstract}
During the past few decades, the fraction of the equity market owned directly by individuals declined significantly. The same period witnessed investment trends that include the growth of indexing as well as shifts by active managers toward lower fees and more index-like investing. I develop an equilibrium model linking these investment trends to the decline in individual ownership, interpreting the latter as a reduction in noise trading. Active management corrects most noise trader-induced mispricing, and the fraction left uncorrected shrinks as noise traders' stake in the market declines. Less mispricing then dictates a smaller footprint for active management.
\end{abstract}

Disciplines

Finance | Finance and Financial Management 


\title{
Investment Noise and Trends
}

\author{
ROBERT F. STAMBAUGH*
}

\begin{abstract}
During the past few decades, the fraction of the equity market owned directly by individuals declined significantly. The same period witnessed investment trends that include the growth of indexing as well as shifts by active managers toward lower fees and more index-like investing. I develop an equilibrium model linking these investment trends to the decline in individual ownership, interpreting the latter as a reduction in noise trading. Active management corrects most noise-trader induced mispricing, and the fraction left uncorrected shrinks as noise traders' stake in the market declines. Less mispricing then dictates a smaller footprint for active management.
\end{abstract}

*Presidential address to the American Finance Association, Philadelphia, Pennsylvania, January 2014. Stambaugh is with the Wharton School of the University of Pennsylvania. The author is grateful to Martijn Cremers, Rick Green, Ron Kaniel, Stijn Van Nieuwerburgh, Antti Petajisto, Nick Roussanov, Luke Taylor, and Yu Yuan for helpful comments or assistance. Special thanks go to Ľuboš Pástor for valuable comments and discussions. 
NOISE TRADING HAS BEEN a familiar concept in finance since the 1980s. In the following decades, noise traders have increasingly populated the finance literature, but their real-life presence in the stock market may have declined. Why? First, noise trading is more often associated with individuals than institutions. Fischer Black describes noise traders as "people who trade ... even though from an objective point of view they would be better off not trading." 1 The behavioral finance literature points to numerous factors that lead individuals to make unproductive investment decisions. Second, there has been a substantial downward trend in the fraction of U.S. equity owned directly by individuals. As displayed in Figure 1, since 1980 that fraction has fallen by more than half, from $48 \%$ to around $20 \%$ based on estimates by French (2008), who also suggests the pool of investors most likely to make mistakes may have thus shrunk. ${ }^{2}$ This decline in individual ownership continues a trend that began essentially at the end of World War II, when households held more than $90 \%$ of U.S. corporate equity. Explanatory factors likely include government tax and retirement policies (Rydqvist, Spizman, and Strebulaev, 2014).

The past few decades also witnessed changes within the investment management industry. Passive investing - "indexing"-became popular as an alternative to active investment management, while active managers, particularly mutual funds, lowered their fees and in aggregate became more index-like in their investing. Active management's loss of market share is evident in Panel A of Figure 2, which plots the fraction of equity mutual fund assets actively managed (thicker line) and the fraction of institutionally owned equity that is actively managed (thinner line). Nearly all equity mutual fund assets were actively managed in 1980, but the fraction dropped to $83 \%$ by 2012 . Over the shorter period for which data are available, the actively managed fraction of institutionally owned equity fell from $81 \%$ in 1986 to $59 \%$ in $2006 .{ }^{3}$ Panel B plots the average percentage fees paid by investors in active mutual funds (thicker line) and the average fee paid by institutional investors for active management. While the fee paid by institutional investors stayed rather flat around $0.4 \%$, the fees paid by mutual fund investors fell substantially, from $2.3 \%$ in 1980 to $1.0 \%$ in 2012, due largely to reductions in (ammortized) load charges.

Active management lost market share to indexing while also becoming more similar to indexing as an investment. For example, Panel C of Figure 1 displays the history since 1980 of the index tracking error for the aggregate portfolio of actively managed equity mutual funds in the dataset constructed by Pástor, Stambaugh, and Taylor (2013). The value plotted for a given year is the annualized standard deviation of the market-adjusted monthly return for the subsequent 60 months. A significant downward trend is evident, with the tracking error falling from $2.2 \%$ in 1980 to $1.2 \%$ in 2006. The trend in active management's becoming less active appears not only in its tracking error but also in its stock holdings. Cremers and Petajisto (2009) define "active share," which summarizes the deviations between an active manager's relative stock weightings and market- 
index weightings. Panel D of Figure 2 plots active share for the aggregate portfolio of active mutual funds from 1980 through 2011. ${ }^{4}$ A significant downward trend is again evident, with active share falling from $38 \%$ in 1980 to $23 \%$ in 2011.

I ask whether the above trends in investment management are consistent with the downward trend in individual equity ownership and an associated decline in noise trading. The basic hypothesis is that less noise trading implies a lower capacity for profitable active management. I explore the validity of this hypothesis by developing an equilibrium model for active management in a market with noise traders. The model is simple in many respects but captures the simultaneity between the amount of mispricing and the amount of active management. I then calibrate the model and find it supports the consistency between the investment trends noted above and a decline in noise trading.

The model implies that active management corrects most of the noise-trader induced mispricing that would otherwise exist. A fraction of the mispricing remains uncorrected, because active managers are impeded by both trading costs and idiosyncratic risk. The remaining mispricing allows active management to earn positive alpha at the expense of noise traders. The fraction of mispricing uncorrected by active management shrinks as the fraction of the equity market owned by noise traders declines. With less mispricing, active management must then have a smaller footprint.

\section{Active Management with Noise Traders}

The model has four types of agents: active managers, investors, noise traders, and intermediaries. In a market with many assets, active managers identify and exploit opportunities to outperform the market benchmark and, in particular, maximize their information ratios. Each manager acts competitively, conditioning on prices as well as his fund's size, while facing convex costs of intermediation when deviating from benchmark asset weightings. Competitive investors allocate their stock-market wealth across the active funds and a passive market-index fund so as to maximize the Sharpe ratio of the resulting combination. Noise traders buy individual stocks directly and do not invest in either active funds or index funds. Intermediaries receive trading costs incurred by active managers but otherwise play no role in the model. The aggregate stock-market wealth of the noise traders equals the fraction $h$ times the total value of the stock market; the investors have aggregate stock-market wealth equal to the fraction $1-h$ of total stock market value.

The model presented joins a literature on delegated portfolio management that is too extensive to survey here. Two studies that are perhaps most closely related, in that they analyze equilib- 
rium prices in an economy with noise traders and delegated management, are Garcia and Vanden (2009) and Petajisto (2009). Garcia and Vanden assume a single risky asset, imperfect competition among managers, and endogenous information acquisition. Petajisto has a given active manager maximize the information ratio while the manager assumes his resulting portfolio characteristics determine investors' overall allocation to active management. In addition to possessing these differences from the current model, neither study includes convex costs associated with establishing active (non-benchmark) positions.

\section{A. Stocks}

The market contains $N$ stocks, and the total supply of each stock equals one share. The model considers a single investment period. Stock $i$ has share price $p_{i}$ at the beginning of the investment period and value $x_{i}$ at the end of the period (including dividends). A share in the market portfolio has end-of-period value $x_{m}=(1 / N) \sum_{i=1}^{N} x_{i}$ and price $p_{m}=(1 / N) \sum_{i=1}^{N} p_{i}$. I assume that

$$
x_{i}=\bar{x}_{i}+\eta_{i},
$$

with $\mathrm{E}\left(\eta_{i}\right)=0$ for $i=1, \ldots, N$. I further assume that the $\eta_{i}$ 's have a risk structure given by

$$
\eta_{i}=p_{i} z+p_{m} \epsilon_{i}, \quad i=1, \ldots, N
$$

where $\mathrm{E}(z)=\mathrm{E}\left(\epsilon_{i}\right)=0, \operatorname{Cov}\left(\epsilon_{i}, \epsilon_{j}\right)=0$ for all $i \neq j$, and

$$
\operatorname{Var}\left(\epsilon_{i}\right)=\left(\frac{p_{i}}{p_{m}}\right) \sigma^{2}, \quad i=1, \ldots, N .
$$

I assume that $(1 / N) \sum_{i=1}^{N} \epsilon_{i} \approx 0$, so that the rate of return on the market portfolio is well approximated as

$$
r_{m}=\mu_{m}+z-1,
$$

where $\mu_{m}=\bar{x}_{m} / p_{m}$, with $\bar{x}_{m}=(1 / N) \sum_{i=1}^{N} \bar{x}_{i}$. The rate of return on stock $i$ is given by

$$
r_{i}=\frac{x_{i}}{p_{i}}-1=\left(\frac{\bar{x}_{i}}{p_{i}}\right)+z+\left(\frac{p_{m}}{p_{i}}\right) \epsilon_{i}-1,
$$

from which we see that $\beta_{i}=\operatorname{Cov}\left(r_{i}, r_{m}\right) / \operatorname{Var}\left(r_{m}\right)=1$. The market-adjusted return on stock $i$ is

$$
R_{i}=r_{i}-\beta_{i} r_{m}=\left(\frac{\bar{x}_{i}}{p_{i}}\right)-\mu_{m}+\left(\frac{p_{m}}{p_{i}}\right) \epsilon_{i} .
$$

The alpha for stock $i$ is therefore equal to

$$
\begin{aligned}
\alpha_{i} & =\mathrm{E}\left(R_{i}\right)=\left(\frac{\bar{x}_{i}}{p_{i}}\right)-\mu_{m} \\
& =\mu_{m}\left(\frac{\bar{p}_{i}-p_{i}}{p_{i}}\right),
\end{aligned}
$$


where

$$
\bar{p}_{i}=\bar{x}_{i} / \mu_{m}
$$

is the expected end-of-period value discounted by the expected market return - the stock's CAPM fair value given that $\beta_{i}=1$. The variance of stock $i$ 's market-adjusted return is

$$
\operatorname{Var}\left(R_{i}\right)=\left(\frac{p_{m}}{p_{i}}\right) \sigma^{2} .
$$

From equations (2), (3), and (9) note that a stock with a relatively higher price has both higher variance of next-period value and lower variance of return. This assumption allows active managers' relative allocations across stocks to depend simply on deviations between prices and fair values (a result presented in the next subsection). Given this specification of variances and the resulting active allocations, the model is most sensibly applied in a setting where prices are normalized to comparable magnitudes in the cross section (e.g., scaled by a fundamental such as book value).

\section{B. Active Managers}

There are $M$ active managers. At the beginning of the period, manager $j$ sets a proportional fee rate equal to $f^{(j)}$. Investors then decide to invest in aggregate the dollar amount $W^{(j)}$ with that manager, whose fee revenue is thus $f^{(j)} W^{(j)}$. Given $W^{(j)}$, manager $j$ chooses allocations across individual stocks to maximize his information ratio, defined as net alpha divided by the standard deviation of market-adjusted return.

Each manager can replicate the market index at zero cost but pays trading costs in order to deviate from those benchmark allocations. These costs represent compensation to liquidity-providing intermediaries for taking short-lived positions to facilitate the ultimate market clearing between managers and noise traders. ${ }^{5}$ Specifically, define the active weight

$$
\phi_{i}^{(j)}=\phi_{A, i}^{(j)}-\phi_{m, i}
$$

where $\phi_{A, i}^{(j)}$ is manager $j$ 's weight in stock $i$, and $\phi_{m, i}$ is stock $i$ 's weight in the market portfolio. (Note $\sum_{i=1}^{N} \phi_{A, i}^{(j)}=\sum_{i=1}^{N} \phi_{m, i}=1$.) The value of stock $i$ represented by the manager's benchmark deviation is $D_{i}^{(j)}=\left|\phi_{i}^{(j)}\right| W^{(j)}$, and the associated trading cost is denoted as $C_{i}^{(j)}$. I assume that the proportional trading cost is given by

$$
\frac{C_{i}^{(j)}}{D_{i}^{(j)}}=c \delta_{i}^{(j)}
$$


where $\delta_{i}^{(j)}$ is the fraction of stock $i$ 's total market value represented by $D_{i}^{(j)}$, and $c$ is a constant. In other words, the proportional trading cost is linear in the amount traded. A linear function for the proportional trading cost in a given stock is entertained, for example, by Kyle and Obizhaeva (2013). That study examines portfolio transition trades and concludes that a linear function fits the data only slightly less well than a nonlinear square-root specification. Those authors also model differences in $c$ across stocks, whereas I suppress such cross-sectional variation for simplicity. With the cost specification in equation (11), we will see below that the manager faces decreasing returns to scale with respect to the size of his assets under management. The model of Berk and Green (2004) features decreasing returns to scale, and a number of studies have investigated the presence of fund-level decreasing returns to scale using mutual fund data. Pástor, Stambaugh, and Taylor (2013) report evidence consistent with fund-level decreasing returns, though not with strong statistical significance when employing methods that avoid econometric biases. ${ }^{6}$ Edelen, Evans, and Kadlec (2007) conclude that trading costs present an important source of scale diseconomies for mutual funds.

The $M$ managers possess identical information, which consists of the $p_{i}$ 's, the $\bar{x}_{i}$ 's, $\sigma$, and $c$. Each of the $M$ managers takes those quantities and $W^{(j)}$ as given. I assume $M$ is finite but large enough to make the price-taking assumption plausible. Each manager chooses allocations across individual stocks to maximize his information ratio, and the following proposition characterizes the results of that maximization.

Proposition 1. Manager $j$ 's active weight in stock $i$ is

$$
\phi_{i}^{(j)}=a^{(j)}\left(\frac{\bar{p}_{i}-p_{i}}{p_{m}}\right),
$$

where

$$
a^{(j)}=\mu_{m}\left(\frac{f^{(j)} p_{m}}{c W^{(j)} \psi}\right)^{1 / 2}
$$

and

$$
\psi=\left(1 / p_{m}\right) \sum_{i=1}^{N} \alpha_{i}^{2} p_{i} .
$$

Trading costs incurred equal fee revenue:

$$
\sum_{i=1}^{N} C_{i}^{(j)}=f^{(j)} W^{(j)} .
$$

Manager j's resulting portfolio has net alpha equal to

$$
\alpha_{A}^{(j)}=\left(\frac{f^{(j)} \psi p_{m}}{c W^{(j)}}\right)^{1 / 2}-2 f^{(j)},
$$


market-adjusted volatility equal to

$$
\sigma_{A}^{(j)}=\sigma\left(\frac{f^{(j)} p_{m}}{c W^{(j)}}\right)^{1 / 2}
$$

and information ratio equal to

$$
I_{A}^{(j)}=\frac{\alpha_{A}^{(j)}}{\sigma_{A}^{(j)}}=\frac{1}{\sigma}\left[\psi^{1 / 2}-2\left(c f^{(j)} W^{(j)} / p_{m}\right)^{1 / 2}\right] .
$$

Proof: See Appendix.

We see from equation (12) that the active allocation to asset $i$ is simply a cross-sectional constant, $a^{(j)}$, multiplied by the deviation of the price from the stock's CAPM fair-value. The manager's resulting alpha and information ratio are both decreasing in assets under management, $W^{(j)}$, confirming the presence of decreasing returns to scale as discussed earlier. The presence of the square root of $W^{(j)}$ in the denominator of $a^{(j)}$ in equation (13) implies that as a given price-taking manager receives more money to manage, he increases $\phi_{i}^{(j)} W^{(j)}$ - the dollar size of his active position in stock $i$-but each additional dollar is deployed less actively than the previous one. Note from equations (16) and (18) that a manager's net alpha and information ratio are increasing in $\psi$, defined in equation (14). As will be discussed later, $\psi$ summarizes the overall amount of mispricing present in the cross-section of stocks.

The first term on the right-hand side of equation (16) is the gross alpha, before fees and trading costs, since equation (15) implies that trading costs lower return by the same amount as the fee rate, $f^{(j)}$. The latter result-that the fraction of the manager's assets spent on trading is equal to the fee rate-occurs because convex trading costs counterbalance a manager's incentive to scale up active positions to lessen the importance of the fee. To see this, let $\phi$ denote the vector of the manager's active weights, let $\alpha$ denote the vector of the $N$ assets' alphas, and let $\Sigma$ denote the variance-covariance matrix of the assets' market-adjusted returns. Note that the elements of $\phi$ sum to zero. With no trading costs and a fee rate of $f$, the manager's information ratio is $I=\left(\phi^{\prime} \alpha-f\right) / \sqrt{\phi^{\prime} \Sigma \phi}$. For any active weights such that $\phi^{\prime} \alpha>0$, the manager's incentive is then to multiply those weights by an arbitrarily large scalar, so that $I$ simply approaches the zero-fee information ratio, $\phi^{\prime} \alpha / \sqrt{\phi^{\prime} \Sigma \phi}$. With convex trading costs such as the specification in equation (11), scaling up the weights becomes increasingly costly. The scaling of $\phi$ is then helpful only to the point where the fee rate is exactly counterbalanced by trading costs as a fraction of assets under management, i.e. where fee revenue equals total trading costs. This implication is consistent with the empirical evidence of Edelen, Evans, and Kadlec (2013), who conclude that mutual funds' annual trading costs as a fraction of net asset value are comparable in magnitude to the funds' expense ratios. 


\section{Investors and Managers in Equilibrium}

Investors allocate their stock-market investments across the active managers and a market index fund so as to maximize the Sharpe ratio of the resulting combination. Investors do not concern themselves with the individual stock $\bar{x}_{i}$ 's, which can be treated as known only by the active managers. Investors simply assess active managers' overall portfolio $\alpha_{A}^{(j)}$,s and $\sigma_{A}^{(j)}$,s. In the main formulation of the model, I assume investors make those assessments correctly. An alternative scenario in which investors err is discussed later.

Each investor chooses an allocation across active managers that produces the maximum information ratio of the resulting active portfolio. That active portfolio is then combined with the market index fund to achieve the highest overall Sharpe ratio. I assume the number of investors is large relative to the number of funds (i.e., thousands of funds, millions of investors), and wealth is sufficiently disperse across investors such that each investor takes each manager's $\alpha_{A}^{(j)}$ and $\sigma_{A}^{(j)}$ as given when making allocation decisions. In other words, investors treat their own individual allocations as having no effect on the $W^{(j)}$ 's in equations (16) through (18).

A key feature of the resulting competitive equilibrium is that each manager receives the same fee revenue, $f^{(j)} W^{(j)}$. To see why, first note that the active (market-adjusted) returns for all managers are perfectly correlated with each other, as equation (12) shows that managers' vectors of active weights are spanned by a common vector. Second, each manager's information ratio, $I_{A}^{(j)}$, is a decreasing function of $f^{(j)} W^{(j)}$, as revealed by equation (18). Now observe, applying basic portfolio theory, that if two managers with perfectly correlated active returns have different $I_{A}^{(j)}$,s, the manager with the higher $I_{A}^{(j)}$ will dominate the other and attract any money flowing to either of the two. As the manager with the higher $I_{A}^{(j)}$ attracts money, however, that manager's $I_{A}^{(j)}$ drops. In equilibrium, money must flow to each manager such that the $I_{A}^{(j)}$,s are the same across managers, and this condition implies, from equation (18), that $f^{(j)} W^{(j)}$ is the same across managers. Managers thus face unit elasticity with respect to their fee rate; those charging a higher rate receive proportionately less money to manage, such that the fee rate is irrelevant to the fee revenue. ${ }^{7}$ If $g$ denotes the common level of fee revenue, $f^{(j)} W^{(j)}$, received by each manager, then the weight of fund $j$ in the aggregate portfolio of active managers is

$$
\omega^{(j)}=\frac{W^{(j)}}{\sum_{j=1}^{M} W^{(j)}}=\frac{g / f^{(j)}}{\sum_{j=1}^{M} g / f^{(j)}}=\frac{\bar{f}}{M f^{(j)}},
$$

where $\bar{f}$ is the harmonic mean of fee rates,

$$
\bar{f}=\left(\frac{1}{M} \sum_{j=1}^{M} \frac{1}{f^{(j)}}\right)^{-1} .
$$


The alpha and market-adjusted return volatility of the aggregate active portfolio are given by

$$
\begin{aligned}
\alpha_{A} & =\sum_{j=1}^{M} \omega^{(j)} \alpha_{A}^{(j)} \\
\sigma_{A} & =\sum_{j=1}^{M} \omega^{(j)} \sigma_{A}^{(j)},
\end{aligned}
$$

noting that equation (22) follows from the previously discussed perfect correlation among the managers' active returns.

Let $y$ denote the fraction of investors' aggregate stock-market wealth that is allocated to active management. Because investors share the same objective-maximimum Sharpe ratio-each investor can achieve that maximum by allocating the fraction $y$ to the aggregate portfolio of active management. In doing so, each investor takes $\alpha_{A}$ and $\sigma_{A}$ as given in the competitive equilibrium. Therefore, as shown by Treynor and Black (1973), the optimal $y$ from an individual investor's perspective is given by

$$
y=\gamma \frac{\alpha_{A}}{\sigma_{A}^{2}}
$$

where

$$
\gamma=\left(\frac{\mathrm{E}\left(r_{m}\right)-r_{f}}{\operatorname{Var}\left(r_{m}\right)}\right)^{-1}
$$

The value of $y$ that delivers equation (23) in equilibrium, for a given mean fee rate $\bar{f}$, is characterized by the following proposition.

Proposition 2. The active allocation y is given by

$$
y=\frac{1}{f} \psi N(1-h)(c / M)\left(\frac{\gamma}{\sigma^{2}+2 \gamma N(1-h)(c / M)}\right)^{2} .
$$

Proof: See Appendix.

Given that each of the $M$ funds receives fee revenue $g=f^{(j)} W^{(j)}$, the aggregate fee revenue is

$$
M g=\left(\sum_{j=1}^{M} \frac{\bar{f}}{f^{(j)}}\right) g=\bar{f}\left(\sum_{j=1}^{M} \frac{g}{f^{(j)}}\right)=\bar{f}\left(\sum_{j=1}^{M} W^{(j)}\right)=(\bar{f} y)(1-h) W_{m}
$$

where $W_{m}$ is the aggregate value of all stocks. Observe from equation (25) that the previously discussed fee irrelevance for individual managers also occurs in aggregate with respect to the mean fee, $\bar{f}$. A higher $\bar{f}$ simply produces a proportionately lower aggregate allocation to active management, leaving the product $\bar{f} y$-and thus aggregate fee revenue-unchanged. This result 
affords a simple explanation for the number of active managers. If the cost to be a manager is equal to $\kappa$, then entry of managers occurs to the point where fee revenue covers that cost, and thus $M=(1 / \kappa)(\bar{f} y)(1-h) W_{m}$.

The following proposition gives the aggregate active portfolio's alpha, market-adjusted volatility, information ratio, and active weight in stock $i$. The latter three quantities are expressed conditional on the aggregate allocation, $y$, as well as in alternative forms that rely on the previous proposition.

Proposition 3. The aggregate portfolio of the active managers has net alpha equal to

$$
\alpha_{A}=\frac{\bar{f} \sigma^{2}}{\gamma N(1-h)(c / M)}
$$

market-adjusted volatility equal to

$$
\sigma_{A}=\left(\frac{\sigma^{2} \bar{f}}{N y(1-h)(c / M)}\right)^{1 / 2}=\frac{\bar{f} \sigma}{\psi^{1 / 2}}\left(2+\frac{\sigma^{2}}{\gamma N(1-h)(c / M)}\right)
$$

and information ratio, $\alpha_{A} / \sigma_{A}$, equal to

$$
I_{A}=\frac{1}{\gamma}\left(\frac{\sigma^{2} \bar{f} y}{N(1-h)(c / M)}\right)^{1 / 2}=\frac{\sigma \psi^{1 / 2}}{\sigma^{2}+2 \gamma N(1-h)(c / M)} .
$$

The portfolio's active weight in stock $i$ is given by

$$
\phi_{i}=\left(\frac{\bar{f} \mu_{m}^{2}}{y N(1-h)(c / M) \psi}\right)^{1 / 2}\left(\frac{\bar{p}_{i}-p_{i}}{p_{m}}\right)=\left(\frac{\sigma_{A} \mu_{m}}{\sigma \psi^{1 / 2}}\right)\left(\frac{\bar{p}_{i}-p_{i}}{p_{m}}\right) .
$$

Proof: See Appendix.

Both $\alpha_{A}$ and $\sigma_{A}$ are proportional to the average fee, $\bar{f}$, which drops out of the information ratio, $I_{A}$, in the second equality in (29). Note that $I_{A}$ is increasing in the mispricing measure $\psi$.

The positive net alpha in equation (27) comes at the expense of the noise traders, whose aggregate portfolio must earn negative gross alpha. This statement follows directly from the identity that the aggregate portfolio of non-indexed investments must earn zero gross alpha, as noted for example by Sharpe (1991) and Fama and French (2010). Those studies also point out that an implication of that identity is a negative net alpha for active management in aggregate, given positive costs of active management. It is important to realize, however, that such a statement involves defining active management as all non-indexed investment. In the model here, that definition would have "active" management encompass the investors' allocation to active managers as well as the holdings of the noise traders. 


\section{Equilibrium Pricing}

The degree of mispricing, summarized by $\psi$ defined in equation (14), depends on stock prices. We see above that $\psi$ enters the allocation to the aggregate active portfolio, which in turn enters that portfolio's market-adjusted volatility, information ratio, and stock weights. Fully understanding those equilibrium quantities requires understanding the model's implications for prices. Accomplishing the latter relies on the market-clearing condition,

$$
h \phi_{H, i}+(1-h) \phi_{S, i}=\phi_{m, i}, \quad i=1, \ldots, N
$$

where $\phi_{m, i}$ is stock $i$ 's market weight, $\phi_{H, i}$ is the stock's weight in the aggregate stock portfolio of the noise traders, and $\phi_{S, i}$ is the stock's weight in the aggregate investor portfolio. The investor weight $\phi_{S, i}$ comprises the allocations to active and passive management: $\phi_{S, i}=y \phi_{A, i}+(1-y) \phi_{m, i}$. The noise-trader weight $\phi_{H, i}$ is treated as exogenous and potentially creates mispricing that active management exploits. I assume $\phi_{H, i} \geq 0$ (no short selling by the noise traders). The role of $\phi_{H, i}$ in a stock's equilibrium price is given by the following proposition.

Proposition 4. The equilibrium price of stock $i$ is

$$
p_{i}=\bar{p}_{i}+\theta\left(\hat{p}_{i}-\bar{p}_{i}\right)
$$

where

$$
\hat{p}_{i}=N p_{m} \phi_{H, i}
$$

is the price for stock $i$ that would prevail in the absence of active management (i.e., when $y=0$ ), and

$$
\theta=\left[1+\frac{(1-h)}{h}\left(\frac{\gamma \mu_{m}}{\sigma^{2} / N+2 \gamma(1-h)(c / M)}\right)\right]^{-1}
$$

Proof: See Appendix.

To understand why $\hat{p}_{i}$ is the price when there is no active management, suppose the investors were to allocate all of their stock-market wealth to passive management, so that $\phi_{S, i}=\phi_{m, i}$. Substituting $\phi_{m, i}$ for $\phi_{S, i}$ in equation (31) and noting $\phi_{m, i}=p_{i} /\left(N p_{m}\right)$ gives $p_{i}=N p_{m} \phi_{H, i}$, which is equal to $\hat{p}_{i}$ in equation (33). Note that $\hat{p}_{i}$ does not depend on the fraction of noise traders, $h$. That is, even a small presence of noise traders could cause large pricing errors when there is no active management.

The price-correction coefficient, $\theta$, is increasing in $h$, meaning that a larger fraction of noise traders in the stock market results in less correction of the mispricing they create. ${ }^{8}$ Note also that 
$\theta$ is increasing in the trading-cost parameter, $c$, implying that lower liquidity results in less price correction. This implication is consistent with evidence that stock prices are more efficient when liquidity is higher, as presented in empirical studies by Chordia, Roll, and Subrahmanyam (2008, 2011) and Chordia, Subrahmanyam, and Tong (2013). The value of $\theta$ is also increasing in $\sigma$, so that higher idiosyncratic volatility results in less price correction. Evidence that higher idiosyncratic volatility is associated with greater mispricing is presented, for example, by Stambaugh, Yu, and Yuan (2013).

The value of $\theta$ is likely to be small as long as the noise-trader fraction, $h$, is not close to 1. In the examples calibrated in the next section, $\theta$ is less than 0.001 . The main reason $\theta$ is small is that both the number of managers, $M$, and the number of stocks, $N$, are fairly large relative to the respective quantities they divide in the denominator of the second term inside the brackets in equation (34). Note that if both $M \rightarrow \infty$ and $N \rightarrow \infty$ as other quantities are held constant, then $\theta \rightarrow 0$. As $N \rightarrow \infty$ the non-market volatility of stocks can be diversified away, presenting potential asymptotic arbitrage in the manner of Ross (1976). Trading costs impede such arbitrage, but as $M \rightarrow \infty$, or equivalently as $\kappa \rightarrow 0$, those trading costs become vanishingly small. (Recall that $\kappa$ is the cost to be an active manager.) The reason is that proportional trading costs decrease with the amount traded, as in equation (11), and the trading amount of each individual manager's benchmark deviation becomes infinitesimal as the number of managers grows. As the opportunities available to each manager approach costless asymptotic arbitrage, the fraction of uncorrected mispricing must vanish, and $\theta \rightarrow 0$. While this comparative static result correctly states the effect of increasing $M$ as $c$ is held constant, I argue later when calibrating the model that it is more reasonable to view the ratio $(c / M)$ as remaining stable when $M$ trends upward.

A small value of $\theta$ implies that active management eliminates virtually all of whatever mispricing the noise traders might produce. Active management thereby provides a substantial externality to society if noise traders would otherwise produce significant mispricing. The mispricing that remains nevertheless supports the active management industry. How large is that industry? Recall that active management's allocation in equation (25) depends on fee rates. For a sufficiently low $\bar{f}$, active management can always receive a large allocation, as long as aggregate fee revenue supports the existence of at least one manager. How much fee revenue gets collected is another question. We see from equation (25) that the fee revenue depends on the amount of equilibrium mispricing, summarized by the value of $\psi$ defined in equation (14). 
The mispricing measure $\psi$ depends on the $p_{i}$ 's and the $\alpha_{i}$ 's. Substituting from equations (7) and (32) into equation (14) gives

$$
\psi=\theta^{2} \mu_{m}^{2} \sum_{i=1}^{N} \frac{\left[\left(\hat{p}_{i}-\bar{p}_{i}\right) / p_{m}\right]^{2}}{\bar{p}_{i} / p_{m}+\theta\left[\left(\hat{p}_{i}-\bar{p}_{i}\right) / p_{m}\right]} .
$$

The average of $\left(\hat{p}_{i}-\bar{p}_{i}\right) / p_{m}$ across the $N$ assets equals 0 , since summing the $\bar{p}_{i}$ 's in equation (8) gives $N p_{m}$, noting $\sum_{i=1}^{N} \bar{x}_{i}=N p_{m} \mu_{m}$, and summing the $\hat{p}_{i}$ 's in equation (33) also gives $N p_{m}$, noting $\sum_{i=1}^{N} \phi_{H, i}=1$. The value of $\psi$ depends on the magnitudes of $\left(\hat{p}_{i}-\bar{p}_{i}\right) / p_{m}$ across assets. Specifying the cross-sectional distribution of those deviations is explored in Section II.

Mispricing in this model refers to the deviation of a stock's price from its CAPM fair-value, $\bar{p}_{i}$, and that fair-value defined in equation (8) depends on $\mu_{m}$, which is (one plus) the expected return on the overall market. Whether or not $\mu_{m}$ also reflects fair pricing of the aggregate expected endof-period value, $\bar{x}_{m}$, is outside the model's scope. Noise traders might also exert systematic effects that impact the market's expected return as well as its volatility (e.g., Delong, Shleifer, Summers, Waldman, 1990, and Shiller, 2000). I take the market's expected return and volatility as exogenous to the model, and in the calibration presented later I simply specify those quantities as constant over time.

\section{E. Investor Error}

The model assumes that investors have rational expectations and correctly assess $\alpha_{A}$ and $\sigma_{A}$, which are the characteristics of the aggregate active portfolio relevant to the allocation decision. The expression for $y$ in equation (25) gives the equilibrium allocation to active management under those correct assessments. Suppose investors err in their assessments. A more extensive model would have investors recognize that possibility and optimize accordingly. I simply consider what happens in the current setting when investors unwittingly allocate suboptimally.

Deviating from the optimal active allocation affects equilibrium prices. The price-correction coefficient, $\theta$ in equation (34), takes a different value — denote it $\theta^{*}$ —and thus the mispricing measure $\psi$ in equation (35) takes a different value-denote it $\psi^{*}$. Suppose the active allocation $y^{*}$ is $\lambda$ times the allocation that is optimal when the mispricing measure under that allocation equals $\psi^{*}$. The following proposition characterizes the resulting prices and the aggregate active portfolio.

Proposition 5. Denote the aggregate allocation to the optimal portfolio of active managers as $y^{*}$. When $y^{*}$ equals $\lambda$ times the allocation that is optimal under the equilibrium prices that result under 
$y^{*}$, the value of $\theta$ in equation (32) is replaced by

$$
\theta^{*}=\left[1+\lambda^{1 / 2} \frac{(1-h)}{h}\left(\frac{\gamma \mu_{m}}{\sigma^{2} / N+2 \gamma(1-h)(c / M)}\right)\right]^{-1} .
$$

The aggregate portfolio of the active managers has net alpha equal to

$$
\alpha_{A}^{*}=\lambda^{-1 / 2}\left[\alpha_{A}-2 \bar{f}\left(\lambda^{1 / 2}-1\right)\right]
$$

market-adjusted volatility equal to

$$
\sigma_{A}^{*}=\left(\frac{\psi}{\lambda \psi^{*}}\right)^{1 / 2} \sigma_{A}
$$

and information ratio equal to

$$
I_{A}^{*}=\frac{\alpha_{A}^{*}}{\sigma_{A}^{*}}=\left(\frac{\psi^{*}}{\psi}\right)^{1 / 2}\left[I_{A}-\frac{2\left(\lambda^{1 / 2}-1\right) \bar{f}}{\sigma_{A}}\right],
$$

where $\alpha_{A}, \sigma_{A}$, and $I_{A}$ are given in equations (27) through (29), and $\psi^{*}$ is given by equation (35) with $\theta$ replaced by $\theta^{*}$. Proof: See Appendix.

Consider, for example, an over-allocation to active managment, so that $\lambda>1$. One effect is greater price correction as compared to the case when $\lambda=1$, since $\theta^{*}$ is decreasing in $\lambda$. The alpha on the active portfolio is also less than when the active allocation is optimal, since $\alpha_{A}^{*}$ is also decreasing in $\lambda$. The decrease in alpha comes from two sources, which can be understood by examining the alpha for a given manager in equation (16). One source is the greater price correction, resulting in a lower value of $\psi$. The other source is the effect of decreasing returns to scale, so that a greater allocation to active management raises each manager's $W^{(j)}$, holding fees constant. Both sources work together to produce an inverse relation between alphas and the allocation to active management. Over-allocation can make the net alpha negative, in which case the fees (paid to managers) and trading costs (paid to intermediaries) are then more than can be made up by the positive gross alpha, despite managers' optimizing with what they are given to manage. The gross alpha is always positive for investors, negative for noise traders, and zero for the weighted combination.

An inverse relation between alphas and the amount of money allocated to the active management industry — industry-level decreasing returns to scale — is proposed and analyzed by Pástor and Stambaugh (2012). Pástor, Stambaugh, and Taylor (2013) find empirical evidence in support of industry-level decreasing returns for actively managed equity mutual funds. 


\section{Modeling Noise Trader Investment}

Within the model, noise traders invest directly in individual stocks rather than through either active or passive managers. In aggregate they own fraction $h$ of the equity market. My empirical proxy for $h$ is the fraction of U.S. equity owned directly by individuals, as displayed in Figure 1.

The other relevant property of noise traders is the extent to which their aggregate allocations to individual stocks deviate from those justified by fair values. If across stocks the magnitudes of $\hat{p}_{i}-\bar{p}_{i}$ are sufficiently large, a nontrivial amount of those deviations can remain uncorrected even though the fraction uncorrected $(\theta)$ is small. The weight $\phi_{H, i}$ in the aggregate portfolio of the noise traders determines the $\hat{p}_{i}$ 's as in equation (33). I view the empirical counterpart for $\phi_{H, i}$ as stock $i$ 's aggregate weight in the direct stock holdings of individuals.

Portfolios of stock held directly by individuals are notoriously undiversified, as observed four decades ago in studies by Blume, Crockett, and Friend (1974), Lease, Lewellen, and Schlarbaum (1974), and Blume and Friend (1975). Further evidence is provided in more recent studies. For example, Polkovnichenko (2005) finds that among households with liquid financial assets in excess of $\$ 1$ million (in 1989 dollars), the households that hold stocks directly typically hold 15 stocks or less. In the remaining income cohorts, the same study finds households that directly own stocks typically hold three stocks or less. ${ }^{9}$ Polkovnichenko also finds that the same households whose direct holdings are undiversified often nevertheless hold a substantial fraction of their financial wealth in diversified mutual funds.

While the typical individual's direct stock holdings are undiversified, the more relevant issue for pricing is the extent to which the low diversification survives aggregation. If the degree to which a given stock is under-weighted or over-weighted is independent across individuals, then those deviations average out when aggregating across many individuals and have little if any effect on prices. In contrast, if there is commonality in direct stock holdings across individuals, the low diversification of investors' portfolios does not completely wash out in aggregate and can therefore impact prices (Shleifer and Summers, 1990).

Evidence of significant commonality in individuals' stock holdings is reported by Feng and Seasholes (2004), Dorn, Huberman, and Sengmueller (2008), and Barber, Odean, and Zhu (2009). The Barber et al. study also concludes that various shared behavioral biases play important roles in producing the commonality. Barber and Odean (2008) find that investors generally favor "attentiongrabbing" stocks that have appeared in news stories or have experienced extreme returns or trading volume. Consistent with that evidence, Fang and Peress (2009) find that stocks with high media coverage earn low returns, especially stocks with relatively high individual ownership (i.e., stocks 
with low ownership by $13 \mathrm{~F}$ filers). In general, the empirical evidence suggests individual investors respond to various events and stimuli in similar ways, due to behavioral biases or constraints on their ability to obtain and process information not readily available. ${ }^{10}$

The evidence for commonality across individual investors is significant but does not fully pin down the degree to which low diversification at the individual level survives aggregation. I adopt a specification that admits a wide range for that outcome. The first step is to observe that the relative pricing error $\left(\hat{p}_{i}-\bar{p}_{i}\right) / p_{m}$ appearing in the mispricing measure $\psi$ in equation (35) can be written as

$$
\left(\hat{p}_{i}-\bar{p}_{i}\right) / p_{m}=N \phi_{H, i}-\bar{x}_{i} / \bar{x}_{m},
$$

using equations (8) and (33) along with the relation $p_{m}=\bar{x}_{m} / \mu_{m}$. I assume that the price and payoff of each stock $i$ is normalized by expected end-of-period value so that $\bar{x}_{i}=\bar{x}_{m}$, and thus

$$
\left(\hat{p}_{i}-\bar{p}_{i}\right) / p_{m}=N \phi_{H, i}-1 \text {. }
$$

In other words, with this normalization, mispricing depends simply on the extent to which aggregate noise-trader allocations deviate from equal weights.

Next define $v_{i}=N \phi_{H, i}$. I approximate the cross-sectional distribution of the $v_{i}$ 's with a continuous Weibull density for $v$. The density is defined for $v \geq 0$, consistent with the assumption that noise-traders do not short. The Weibull distribution has two parameters, determining the distribution's scale and shape. ${ }^{11}$ In this application, $\mathrm{E}(v)=1$, given that $\sum_{i=1}^{N} \phi_{H, i}=1$, so there is one free parameter $k$ that determines the distribution's shape. The resulting family of densities is illustrated in Figure 3. As $k$ becomes large, the density concentrates around $v=1$, yielding the completely diversified portfolio that puts equal weights on all stocks. As $k$ becomes small, the mass concentrates toward zero and skewness increases, yielding an undiversified portfolio that puts low weights on most stocks and large weights on a relative few. The mispricing measure $\psi$ in equation (35) can be written as

$$
\psi=\theta^{2} \mu_{m}^{2} \sum_{i=1}^{N} \frac{\left(v_{i}-1\right)^{2}}{1+\theta\left(v_{i}-1\right)},
$$

using equation (41) and the definition $v_{i}=N \phi_{H, i}$. The analog in terms of the continuous $v$ is

$$
\psi=\theta^{2} \mu_{m}^{2} N \mathrm{E}\left\{\frac{(v-1)^{2}}{1+\theta(v-1)}\right\} .
$$

I take equation (43) as a reasonable proxy for equation (42) for large $N$, which is nearly 7,000 in the calibration below. 


\section{Trends and the Model}

\section{A. Data Trends}

The model defines $h$ as the fraction of equity owned by noise traders, and in the data I take $h$ to be the fraction of equity owned by individuals. My objective is to focus on trends rather than fluctuations. ${ }^{12}$ In order to isolate the trend in individual ownership, I specify the values for $h$ as the points on a linear trend fit through the actual series of individual holdings, displayed as the dotted line in Figure 1. The quantity $\sigma_{A}$ in the model is the active portfolio's market-adjusted return volatility, and in the data I take $\sigma_{A}$ to be the tracking error of the aggregate portfolio of active mutual funds. As with $h$, I take the values of $\sigma_{A}$ to be points on a linear trend through the series of mutual-fund tracking errors discussed earlier, and Panel $\mathrm{C}$ of Figure 4 displays that result. Similarly, I fit a trend line through active share, as displayed in Panel D of Figure 4.

I also want to isolate trends from year-to-year fluctuations when constructing the empirical analogs for the fee rate, $\bar{f}$, and the active allocation, $y$. From the model's perspective, an inconvenient feature of the real world is that investors served by professional money management are essentially split into two segments: retail (mutual fund) investors and institutional investors such as pension funds. The current model does not admit such segmentation. Extending the model to do so could be a worthwhile, but for this study I make a simplifying compromise with the data. Specifically, for the active allocation, I first fit separate trend lines through the mutual fund series and the institutional series and then take the average of those two trend lines as the input for $y$ in the model. I do the same thing for fee rates to construct the input for $\bar{f}$. The resulting trend lines are displayed in Panels A and B of Figure 4.

The objective of averaging the trends across the retail and institutional segments is to have the data discipline the single resulting trend in a manner that, while rudimentary, is representative of changes in investment management within each segment. An alternative would be to ignore the segmentation and simply combine the two segments into one pool, weighting by the respective sizes of each segment. This approach seems less desirable in the context of the allocation decisions being modeled here. Although many retail investors have an indirect stake in institutional portfolios through their pensions, etc., they generally cannot directly access the lower-fee institutional active management when allocating between active and passive management. Similarly, institutions making that allocation decision do not face the higher fees of the retail segment. If the segments are instead pooled, the resulting composite active fee rate actually trends upward, contrary to the experience of an investor in either segment. The reason for the upward trend is the relatively higher rate of growth of mutual funds that accompanied the migration from direct 
individual ownership. French (2008) observes that this growth in the retail segment's share of the investment management industry is a major factor in keeping society's overall cost of active investment relatively constant over the 1980-2006 period, despite reductions in trading costs and mutual-fund load fees. ${ }^{13}$

\section{B. Parameter Values}

The model parameters are $\mu_{m}, \gamma, N, \sigma, c, M$, and $k$. The first four are specified using straightforward empirical counterparts. The value of $\mu_{m}=1.065$ is one plus the average return from 1980 through 2012 on the value-weighted NYSE/AMEX/NASDAQ portfolio, while the value of $\gamma=0.7238$ is the variance of that portfolio over the same period $\left(0.171^{2}\right)$ divided by the portfolio's average return in excess of the one-month Treasury Bill rate (0.0404). The value of $N=6893$ is the average number of stocks on NYSE/AMEX/NASDAQ over the 1980-2012 period. (The number of stocks increases and then decreases over that period but does not exhibit a significant trend; the numbers in 1980 and 2012 are 5006 and 5499 respectively.) The data used to construct all of the above values are obtained from CRSP. For the value of $\sigma=0.188$, I take the average annual cross-sectional mean idiosyncratic volatility for all CRSP stocks from 1981 through 2008, using results reported by Brandt, Brav, Graham, and Kumar (2010).

Specifying values for the remaining parameters $c, M$, and $k$ is less straightforward. In all of the model's equilibrium quantities, as given in Propositions 2 through 5, the parameters $c$ and $M$ appear only as the ratio $c / M$. I assume that $c / M$ is constant over time in the calibration explored here. This is a nontrivial assumption, as opposed to assuming $c$ is constant, since the number of active managers $(M)$ grew considerably over the 1980-2012 period. To understand the reasoning, recall from equation (11) that an individual manager's intermediation cost of taking an active position of (dollar) amount $D_{i}$ in stock $i$ is $c \times \delta_{i} \times D_{i}$, where $\delta_{i}$ is the fraction that $D_{i}$ represents of stock $i$ 's total market capitalization. The relevant question is the extent to which that intermediation cost depends on how many other active managers wish to take a similar active position. It seems more likely that growth in the number of managers competing for intermediation in the same direction increases the cost of taking a position representing any given fraction $\delta_{i}$ of the stock, as opposed to leaving that cost unaffected. I assume for tractability that the cost increase is simply proportionate, so that $c / M$ is constant.

To specify the value for $c / M$, I rely on the first equality in (28), which implies

$$
\frac{c}{M}=\frac{\sigma^{2} \bar{f}}{\sigma_{A}^{2} N y(1-h)} .
$$


I then evaluate equation (44) with $h, y, \bar{f}$, and $\sigma_{A}$ set to their 1996 (mid-sample) points on the trend lines in Figure 1 and Panels $\mathrm{A}$ through $\mathrm{C}$ in Figure 4. This calculation gives $c / M=4.37 \times 10^{-4}$. One can interpret this value in the context of the implied separate value for $c$ by conditioning on $M$ in that same mid-sample year. To get a rough estimate of $M$, I add the number of active mutual funds in the dataset constructed by Pástor, Stambaugh, and Taylor (2013) to the number of institutions other than mutual funds filing Form 13F with the SEC, as provided by Thomson Reuters. In 1996 this estimate of $M$ equals 2212, giving an implied value of $c=0.967$. In other words, at this mid-sample value, the proportional cost of taking an active position is approximately equal to the position's fraction of the stock's total market capitalization.

The parameter $k$ determines the distribution of noise-trader weights, as in Figure 3. I specify $k$ as the value that solves the equilibrium relation for $y$ in equation (25) when $h, y$, and $\bar{f}$ again equal the 1996 points on the trend lines in Figure 1 and in Panels A through $\mathrm{C}$ of Figure 4. The parameter $k$ enters the relation for $y$ via the mispricing measure, $\psi$, and the value of $\psi$ for a given $k$ is evaluated numerically using equation (43). The result of this calculation gives $k=0.215$, yielding a distribution for noise-trader weights very close to the case of $k=0.2$ plotted in Figure 3. Recall that a distribution with that shape arises from commonality in portfolios across noise traders, such that low diversification at the individual level survives aggregation to a substantial degree.

\section{Model Trends Versus the Data}

I next explore the extent to which the model, calibrated using a single mid-sample year, can produce the investment trends observed in the years before and after. I first compute the implied values of the market-adjusted volatility (tracking error) $\sigma_{A}$ conditional on the sample trend values for $h, y$, and $\bar{f}$. These values for $\sigma_{A}$ do not depend on the value specified for the parameter $k$. I then examine the implied values for the active allocation, $y$, conditional on the trend values for $h$ and $\bar{f}$ and all of the parameters.

The model's implied values for active management's tracking error computed using equation (28) are plotted as the dashed line in Figure 5. The implied $\sigma_{A}$ 's exhibit a significant negative trend, declining from nearly $1.8 \%$ in 1980 to $1.2 \%$ in 2012 . Moreover, the decline is only slightly less steep than the data-based trend, which declines from nearly $2 \%$ in 1980 to $1 \%$ in 2012 . It appears that the model as calibrated does indeed produce a declining trend in tracking error that it is fairly similar to what the mutual-fund data exhibit.

The product $y \bar{f}$ is determined in equilibrium, but the active allocation, $y$, and the fee rate, $\bar{f}$, 
are not determined separately. I therefore condition on the sample trend values for $\bar{f}$ and then compute the values for $y$ using equation (25). The model's implied $y$ values are plotted as the dashed line in Panel A of Figure 6. The model's $y$ values exhibit a clear declining trend, so the model's implications are in qualitative agreement with the trend in the data. Also apparent in the plot is that the model as calibrated is in a sense too successful in producing such a trend: the model's trend values for $y$ decline from about $120 \%$ in 1980 to less than $50 \%$ in 2012, whereas the data trend in $y$ over those same years declines from $92 \%$ to $68 \%$. From equation (25), we can see that for the given decline in $h$, closer agreement between the model and data trends in $y$ would require either a steeper decline in the fee rate, $\bar{f}$, or a less steep decline in the mispricing measure, $\psi$.

The mispricing measure, $\psi$ in equation (43), declines as $h$ declines while $k$ is held constant. The reason for the decline in $\psi$ in that setting is simply because $\theta$ falls as $h$ falls. Recall that $\theta$, given in equation (34), is the fraction of noise-trader mispricing left uncorrected, and $\theta$ is an increasing function of $h$. One might ask whether assuming that $k$ remains constant while $h$ declines is the most reasonable assumption a priori. As $h$ declines and presumably the population of noise traders shrinks, one might expect that aggregation across noise traders becomes at least somewhat less successful in washing out the low diversification of individual noise traders. In other words, as $h$ declines, one might expect the density of $v$, illustrated previously in Figure 3, to shift mass toward zero and become more positively skewed. Such a shift corresponds to a decrease in the parameter $k$.

I ask how much $k$ must decline over the sample period in order to achieve a close correspondence between the model-implied and data-based trends in $y$. Recall that $k$ is held constant at 0.215 throughout the sample period in producing the model values of $y$ in Panel A of Figure 6. If $k$ again equals that value in the mid-sample year 1996 but instead declines linearly with time, from $k=0.228$ in 1980 to $k=0.201$ in 2012 , then the model's implied trend in $y$ essentially matches that of the data, as shown in Panel B of Figure 6. The densities for $v$ corresponding to the 1980 and 2012 values of $k$ are plotted in Figure 7. Viewed from this perspective, the required decline in $k$ seems rather modest. Moreover, even with this trend in $k$, the decline in $\theta$ due to the decline in $h$ still produces a substantial overall decline in the mispricing measure $\psi$, which drops more than $50 \%$ between 1980 and 2012, from 0.09 to 0.04 .

Active share of the aggregate portfolio is computed $A S=(1 / 2) \sum_{i=1}^{N}\left|\phi_{i}\right|$, as defined by Cremers and Petajisto (2009). Substituting the second expression for $\phi_{i}$ in equation (30) gives the 
model's implied active share,

$$
\begin{aligned}
A S & =\frac{1}{2}\left(\frac{\sigma_{A} \mu_{m}}{\sigma \psi^{1 / 2}}\right) \sum_{i=1}^{N}\left|\frac{\bar{p}_{i}-p_{i}}{p_{m}}\right| \\
& =\frac{1}{2}\left(\frac{\sigma_{A} \mu_{m}}{\sigma \psi^{1 / 2}}\right) \theta \sum_{i=1}^{N}\left|N \phi_{H, i}-1\right|,
\end{aligned}
$$

where the second equality applies equation (32) and then (41). Recall that the cross section of $N \phi_{H, i}-1$ is approximated by the continuous Weibull variable $v$. The resulting calculation of active share then becomes

$$
A S=\frac{N \theta}{2}\left(\frac{\sigma_{A} \mu_{m}}{\sigma \psi^{1 / 2}}\right) \mathrm{E}\{|v|\} .
$$

The dashed line in Figure 8 plots the model-implied active share in equation (46) for the setting with $k$ declining as in Panel B of Figure 6. The model $A S$ values exhibit a downward trend with a slope similar to the data values. The model values are generally about twice as large as the data values, but the fact that they are even of a similar magnitude seems noteworthy, as there is no use of active share in calibrating the model. While the model values exceed the sample $A S$ values for the aggregate active portfolio, they are lower than the values of the average individual fund active share that Cremers and Petajisto (2009) report in addition to the aggregate values.

\section{Negative Alpha}

The model implies that $\alpha_{A}$ in equation (27) is positive. This implication for the aggregate net alpha is at odds with empirical evidence on the performance of active management. Actively managed equity mutual funds - the segment of active management for which returns data are most available — have historically provided investors with net average returns below those on passive benchmarks. For example, the value-weighted portfolio of the actively managed mutual funds in the dataset constructed by Pástor, Stambaugh, and Taylor (2013) has an annualized estimated net alpha equal to $-0.31 \%$ (t-statistic: -1.06 ) for the $1980-2011$ period. $^{14}$

A positive net alpha occurs in equilibrium if investors have rational expectations and allocate the correct amount to active management. As discussed earlier, if investors allocate too much, the resulting alpha is lower. Consider, for example, the first year of the sample period, 1980. Under the above calibration of the model (including the modest decline in $k$ ), the value of $\alpha_{A}$ in equation (27) is equal to $0.039 \%$ per annum. In other words, under rational expectations, the net alpha is slightly positive, just large enough (recalling equation 23) to induce an allocation $(y)$ of $91 \%$ to active management when that portfolio's volatility $\left(\sigma_{A}\right)$ is $1.75 \%$ and the index fund has $\gamma=0.7238$. (The values for $\sigma_{A}$ and $y$ correspond to the model's 1980 implied values in Figure 5 and Panel B 
of Figure 6; recall that $\gamma$ is the market's variance divided by its expected excess return.) Suppose that an allocation of $91 \%$ is higher than it should be given the true degree of mispricing, and that the correct value of $y$ is instead $70 \%$, so that $\lambda$ in Proposition 5 equals $1.3(=91 / 70)$. Applying equation (37) then gives a resulting net alpha of $\alpha_{A}^{*}=-0.31 \%$, equal to the sample estimate for the post-1980 period. As discussed earlier, $\alpha_{A}^{*}$ is decreasing in $\lambda$, so active managers face decreasing returns to scale with respect to the size of their industry.

While it is appealing to assume that investors have rational expectations and allocate correctly, Pástor and Stambaugh (2012) show that the presence of industry-level decreasing returns to scale presents investors with an inference problem that can involve slow learning about the degree of decreasing returns and thus slow convergence to the correct allocation. Pástor and Stambaugh analyze this learning problem with a constant true underlying relation between the size of the active management industry and active management's alpha. In the current setting, that relation changes over time as the noise trader fraction $h$ changes. Incorporating learning is beyond this study's scope, but one might suspect that moving from a stable returns-to-scale relation to one that shifts through time can only make investors' inference problem more difficult. It seems reasonable to entertain over-allocation to active management as the source of the negative estimated historical alpha. One might further entertain the retail segment of investors as being a potential source of over-allocation, at least compared to the institutional segment, given that the retail segment has allocated a greater fraction to active management despite being subject to higher fee rates.

It is important to note that in general the rational reaction by investors in aggregate to negative realized alpha is not to abandon active management entirely. Allocating too little to active management leaves investors with a lower Sharpe ratio than they could otherwise obtain, since the equilibrium alpha on active management is then too high. Of course, from a societal perspective, allocating too little to active management also creates a negative externality, in that equilibrium prices have larger errors and thus the allocation of society's resources across firms can be less efficient.

\section{E. Fees, Noise Traders, and Future Trends}

As discussed previously (Proposition 2), the model uniquely determines the product of the fee rate, $f$, and the active allocation, $y$, but does not determine those quantities individually. The product $f y$ is the fraction of investors' stock market wealth that active managers receive as fee revenue, while the product $(1-h) f y$ is the fraction of total stock market value received as fee revenue. The noise-trader fraction, $h$, enters the right-hand side of equation (25) at several places, including 
$\psi$, and the latter quantity is computed using numerical integration to evaluate the expectation in equation (43). As a result, the dependence of fee revenue on $h$ is not straightforward to characterize analytically, but the function is easily plotted. Figure 9 plots both $f y$ and $(1-h) f y$ as a function of $h$, with the model parameters equal to those calibrated earlier at the mid-sample values. Fee revenue as a fraction of investors' stock market wealth, $f y$, is increasing in the noise trader fraction, $h$, and fee revenue goes to zero as $h$ does. Fee revenue as a fraction of total stock market value, $(1-h) f y$, is increasing in $h$ at lower $h$ values but decreasing at higher values. In other words, as investors own a progressively smaller fraction of the stock market, the fee revenue they pay eventually falls even though it represents an ever higher fraction of their stock market wealth.

As a final perspective on trends, I explore what the model implies if previous trends continue into the future. The basic theme of this study is that a decline over time in the presence of noise traders, proxied here by the fraction of equity owned directly by individuals, brings with it changes in the characteristics of professional active management. If the noise trader fraction, $h$, continues to decline, how might the investment landscape continue to change? To investigate this question, I simply extrapolate the linear trend in $h$ into the future. That declining trend hits $h=0$ in about 28 years, around the year 2042. Because $y$ and $f$ are not separately determined, as before I condition on one quantity and then examine the other. For this exercise, I condition on $y$ and imagine that active management's share, relative to indexing, continues its decline, following the same linear trend fit through 2012. By 2042, active management's share of professional management then declines to about $45 \%$. These trends in $h$ and $y$ are displayed in Panel A of Figure 10.

Given the hypothetical trends in $h$ and $y$, I compute the model's implied future values for the average fee, $\bar{f}$, and the active tracking error, $\sigma_{A}$. These values are plotted in Panel B of Figure 10. Observe that both $\bar{f}$ and $\sigma_{A}$ approach zero as $h$ approaches zero. In other words, in order to manage a non-trivial share of investors' stock market wealth, active managers must behave increasingly like index funds (assumed to have zero fees in the model).

\section{Conclusions}

In the equilibrium model developed and calibrated here, active management corrects most of the noise-trader induced mispricing that would otherwise exist. A fraction of the mispricing remains uncorrected, because active managers are impeded by both risk and trading costs. The remaining mispricing allows investors who allocate a portion of their wealth to active management to profit (earn alpha) at the expense of noise traders. The fraction of mispricing that remains uncorrected by active management shrinks as the fraction of the equity market owned by noise traders 
declines. The decline in noise trading thus dictates a smaller footprint for active management. That smaller footprint can involve lower fees and lower tracking error, or a lower allocation by investors to active management, or a combination of those effects. For individual active managers as well as their overall industry, the fee revenue collected is invariant to the fee rate; a higher fee rate simply means that investors allocate correspondingly less money to be managed. Both the alpha and the market-adjusted volatility of the aggregate active portfolio are proportional to the fee rate, which therefore drops out of that portfolio's information ratio.

Active management in recent decades experienced downward trends in (i) market share, (ii) fee rates, (iii) tracking error, and (iv) deviations from benchmark stock weightings (active share). The model contains two unknown parameters in addition to those that have straightforward empirical counterparts. The first parameter governs trading costs while the second parameter characterizes the extent to which the low diversification typical of individual investors survives aggregation. These two parameters are calibrated using mid-sample (1996) levels for the fraction of individual equity ownership, the market share of active management, the active fee rate, and tracking error. Implied values for the other years in the 1980-2012 sample period reveal that the downward trends in active management are mutually consistent with a decline in the fraction of the market owned by individual investors, viewed here as noise traders. If individual ownership and thus noise trading continue to decline, the model implies that both fee revenue and tracking error must decline as well, just to keep active management's market share from declining more rapidly in the future than it did during the 1980-2012 period.

It is well known that active management in aggregate has historically under-performed passive benchmarks. If investors unwittingly allocate more to active management than is justified by the current fee rate and degree of noise-trader mispricing, then the resulting alpha on active management can become negative. In other words, the active management industry in the model exhibits decreasing returns to scale. If investors must arrive at the appropriate investment level by inferring empirically the effect of scale on performance, adjustment to the correct level of investment can be slow, as shown by Pástor and Stambaugh (2012). A prescription that all investors react to the historical under-performance by simply reallocating everything to passive investing would be ill-advised, however, at least in the context of the model. Unless there is zero noise trading, the result would leave an unexploited positive alpha for potential active investing as well as fully uncorrected noise-trader induced mispricing. The latter would presumably impose a significant negative externality arising from allocational inefficiency.

The simple model presented here abstracts from potentially important considerations in addition to the retail-versus-institutional segmentation discussed earlier. Incorporating heterogeneity 
in skill and information across investment managers is likely a potentially important extension. Also, the current model takes the information possessed by active managers as exogenous. Another worthwhile extension would be to make information acquisition endogenous, possibly an increasing function of fee revenue. These and other issues leave much for future research. 


\section{Appendix}

Proof of Proposition 1: First note that before fees and costs, the manager's market-adjusted rate of return is $\sum_{i=1}^{N} \phi_{A, i}^{(j)} R_{i}=\sum_{i=1}^{N} \phi_{i}^{(j)} R_{i}$, since $\sum_{i=1}^{N} \phi_{m, i} R_{i}=0$. The fee reduces this rate of return by $f^{(j)}$. The manager's trading cost for asset $i$ is $C_{i}^{(j)}=c \delta_{i}^{(j)}\left|\phi_{i}^{(j)}\right| W^{(j)}=c\left(\left|\phi_{i}^{(j)}\right| W^{(j)} / p_{i}\right)\left|\phi_{i}^{(j)}\right| W^{(j)}$, and thus trading costs reduce the manager's rate of return by $\left(\sum_{i=1}^{N} C_{i}^{(j)}\right) / W^{(j)}=c W^{(j)} \sum_{i=1}^{N}\left(\phi_{i}^{(j)}\right)^{2} / p_{i}$. The manager's net market-adjusted return is therefore

$$
R_{A}^{(j)}=\sum_{i=1}^{N} \phi_{i}^{(j)} R_{i}-f^{(j)}-c W^{(j)} \sum_{i=1}^{N}\left(\phi_{i}^{(j)}\right)^{2} / p_{i},
$$

So

$$
\alpha_{A}^{(j)}=\sum_{i=1}^{N} \phi_{i}^{(j)} \alpha_{i}-f^{(j)}-c W^{(j)} \sum_{i=1}^{N}\left(\phi_{i}^{(j)}\right)^{2} / p_{i}
$$

and

$$
\sigma_{A}^{(j)}=\left[\sum_{i=1}^{N}\left(\phi_{i}^{(j)}\right)^{2}\left(\frac{p_{m}}{p_{i}}\right) \sigma^{2}\right]^{1 / 2},
$$

where the last equality uses equation (9) and the property that the $R_{i}$ 's are mutually uncorrelated. To streamline notation, hereafter suppress the superscript $(j)$ and define the $N$-element vectors $\alpha$ and $\phi$, whose $i$-th elements equal $\alpha_{i}$ and $\phi_{i}^{(j)}$ respectively. Also define the $N \times N$ matrix $P$ with $i$-th diagonal element equal to $p_{i}$ and all non-diagonal elements equal to zero. The portfolio parameters in equations (A2) and (A3) can then be rewritten as

$$
\alpha_{A}=\phi^{\prime} \alpha-f-c W \phi^{\prime} P^{-1} \phi
$$

and

$$
\sigma_{A}=p_{m}^{1 / 2} \sigma\left(\phi^{\prime} P^{-1} \phi\right)^{1 / 2}
$$

The manager chooses the vector of active weights $\phi$ to maximize $I_{A}=\alpha_{A} / \sigma_{A}$ subject to $\iota^{\prime} \phi=0$, where $\iota^{\prime}=\left(\begin{array}{llll}1 & 1 & \cdots & 1\end{array}\right)$. (Recall that the manager takes $\alpha, P$, and $W$ as given.) The corresponding Lagrangian is

$$
\mathcal{L}=\frac{\phi^{\prime} \alpha-f-c W \phi^{\prime} P^{-1} \phi}{p_{m}^{1 / 2} \sigma\left(\phi^{\prime} P^{-1} \phi\right)^{1 / 2}}-\tilde{\xi}\left(\iota^{\prime} \phi\right),
$$

Differentiating with respect to $\phi$ and multiplying through by $p_{m}^{1 / 2} \sigma\left(\phi^{\prime} P^{-1} \phi\right)^{1 / 2}$ gives

$$
\alpha-2 c W P^{-1} \phi-\frac{\phi^{\prime} \alpha-f-c W \phi^{\prime} P^{-1} \phi}{\phi^{\prime} P^{-1} \phi} P^{-1} \phi-\xi \iota=0,
$$

where $\xi$ is the rescaled Lagrange multiplier. Multiplying through by $P$ and rearranging gives

$$
\phi=\left(c W+\frac{\phi^{\prime} \alpha-f}{\phi^{\prime} P^{-1} \phi}\right)^{-1} P(\alpha-\xi \iota) .
$$


Note that since the market-weighted combination of the $\alpha_{i}$ 's is zero, $\iota^{\prime} P \alpha=0$. Therefore, since $\iota^{\prime} \phi=0$, multiplying both sides of equation (A8) by $\iota^{\prime}$ implies $\xi=0$, and thus

$$
\phi=\left(c W+\frac{\phi^{\prime} \alpha-f}{\phi^{\prime} P^{-1} \phi}\right)^{-1} P \alpha .
$$

Multiplying both sides of equation (A9) by $\phi^{\prime} P^{-1}$ and rearranging gives

$$
\phi^{\prime} P^{-1} \phi=\frac{f}{c W}
$$

which implies equation (15), since total costs equal $c W^{2} \phi^{\prime} P^{-1} \phi$. Substituting equation (A10) into equation (A9) gives

$$
\phi=\frac{f}{c W \phi^{\prime} \alpha} P \alpha
$$

Multiplying both sides of equation (A11) by $\alpha^{\prime}$ and then solving for $\phi^{\prime} \alpha$ gives

$$
\phi^{\prime} \alpha=\left(\frac{f}{c W}\right)^{1 / 2}\left(\alpha^{\prime} P \alpha\right)^{1 / 2}=\left(\frac{f p_{m}}{c W}\right)^{1 / 2} \psi^{1 / 2},
$$

which when substituted into equation (A11) gives

$$
\phi=\left(\frac{f p_{m}}{c W}\right)^{1 / 2} \psi^{-1 / 2} \frac{1}{p_{m}} P \alpha
$$

Equation (A13) gives equations (12) and (13), noting from equation (7) that $\left(p_{i} / p_{m}\right) \alpha_{i}=\mu_{m}\left(\bar{p}_{i}-\right.$ $\left.p_{i}\right) / p_{m}$. Substituting from equations (A10) and (A12) into equation (A4) gives

$$
\alpha_{A}=\left(\frac{f p_{m}}{c W}\right)^{1 / 2} \psi^{1 / 2}-f-c W \frac{f}{c W},
$$

which is equivalent to equation (16). Substituting from equation (A10) into equation (A5) gives equation (17). Equation (18) follows directly when dividing equation (16) by equation (17).

Proof of Proposition 2: Applying equation (21) to equation (16), using the fund weight $\omega^{(j)}$ in equation (19), gives

$$
\begin{aligned}
\alpha_{A} & =\sum_{j=1}^{M} \frac{\bar{f}}{M f^{(j)}}\left[\left(\frac{f^{(j)} p_{m} \psi}{c W^{(j)}}\right)^{1 / 2}-2 f^{(j)}\right]=\sum_{j=1}^{M} \frac{\bar{f}}{M f^{(j)}}\left[\left(\frac{f^{(j)} p_{m} \psi}{c g / f^{(j)}}\right)^{1 / 2}-2 f^{(j)}\right] \\
& =\bar{f}\left[\left(\frac{\psi}{c g / p_{m}}\right)^{1 / 2}-2\right]=\bar{f}\left[\left(\frac{\psi}{c \bar{f} y(1-h) N / M}\right)^{1 / 2}-2\right]
\end{aligned}
$$

where the last equality uses the relation for $g$ as defined earlier and used in equation (19),

$$
g=\bar{f} y(1-h) p_{m} N / M
$$


which follows from the fact that since the aggregate value of the stock market is $N p_{m}$, the aggregate value of the amount invested in active management is equal to $y(1-h)\left(N p_{m}\right)=\sum_{j=1}^{M} W^{(j)}=$ $\sum_{j=1}^{M} g / f^{(j)}=M g / \bar{f}$, using equation (20). Similarly, applying equation (22) to equation (17) gives

$$
\begin{aligned}
\sigma_{A}^{2} & =\left[\sum_{j=1}^{M} \frac{\bar{f}}{M f^{(j)}}\left(\frac{\sigma^{2} f^{(j)} p_{m}}{c W^{(j)}}\right)^{1 / 2}\right]^{2}=\left[\sum_{j=1}^{M} \frac{\bar{f}}{M f(j)}\left(\frac{\sigma^{2} f^{(j)} p_{m}}{c g / f^{(j)}}\right)^{1 / 2}\right]^{2} \\
& =\left[\frac{\sigma \bar{f}}{c g / p_{m}}\right]^{2}=\frac{\sigma^{2} \bar{f}^{2}}{\bar{f} y(1-h) N(c / M)}=\frac{\sigma^{2} \bar{f}}{y(1-h) N(c / M)}
\end{aligned}
$$

Applying the equilibrium condition $y=\gamma\left(\alpha_{A} / \sigma_{A}^{2}\right)$ in equation (23) then requires that $y$ solves

$$
\begin{aligned}
y & =\gamma \frac{\bar{f}\left[\left(\frac{\psi}{c f y(1-h) N / M}\right)^{1 / 2}-2\right]}{\frac{\bar{f} \sigma^{2}}{c y(1-h) N / M}} \\
& =\frac{\gamma}{\sigma^{2}}\left[y^{1 / 2}\left(\frac{c(1-h) N / M}{\bar{f}}\right)^{1 / 2} \psi^{1 / 2}-2 c y(1-h) N / M\right],
\end{aligned}
$$

which is readily verified to have the solution in equation (25).

Proof of Proposition 3: Substituting $\bar{f} y$ from equation (25) into the last expression in equation (A15) gives

$$
\alpha_{A}=\bar{f}\left[\psi^{1 / 2}\left(c \psi N(1-h)(c / M)\left(\frac{\gamma}{\sigma^{2}+2 \gamma N(1-h)(c / M)}\right)^{2}(1-h) N / M\right)^{-1 / 2}-2\right],
$$

and simplifying gives equation (27). The first equality in equation (28) is given by the last expression in equation (A17). Substituting $y$ from equation (25) into that expression gives

$$
\sigma_{A}=\sigma \bar{f}\left(\psi N(1-h)(c / M)\left(\frac{\gamma}{\sigma^{2}+2 \gamma N(1-h)(c / M)}\right)^{2}(1-h) N(c / M)\right)^{-1 / 2},
$$

and simplifying gives the second equality in (28). It is straightforward to verify that dividing the right-hand side of equation (27) by the rightmost expression equation (28) gives the second equality in (29). From equations (12), (13), and (19), the aggregate active weight in stock $i$, $\phi_{i}=\sum_{j=1}^{M} \omega^{(j)} \phi_{i}^{(j)}$, is given by

$$
\begin{aligned}
\phi_{i} & =\sum_{j=1}^{M} \frac{\bar{f}}{M f^{(j)}} \mu_{m}\left(\frac{f^{(j)} p_{m}}{c W^{(j)} \psi}\right)^{1 / 2}\left(\frac{\bar{p}_{i}-p_{i}}{p_{m}}\right) \\
& =\bar{f} \mu_{m}\left(\frac{1}{(c / M) \bar{f} y(1-h) N \psi}\right)^{1 / 2}\left(\frac{\bar{p}_{i}-p_{i}}{p_{m}}\right)
\end{aligned}
$$


where the second equality substitutes $W^{(j)}=g / f^{(j)}$ and then applies equation (A16). This is the first equality given in (30). To obtain the second equality, substitute for $\bar{f} y$ from equation (25), which gives

$$
\begin{aligned}
\phi_{i} & =\bar{f} \mu_{m}\left((c / M) \psi N(1-h)(c / M)\left(\frac{\gamma}{\sigma^{2}+2 \gamma N(1-h)(c / M)}\right)^{2}(1-h) N \psi\right)^{-1 / 2}\left(\frac{\bar{p}_{i}-p_{i}}{p_{m}}\right) \\
& =\bar{f} \mu_{m} \psi^{-1}\left(2+\frac{\sigma^{2}}{\gamma N(1-h)(c / M)}\right)\left(\frac{\bar{p}_{i}-p_{i}}{p_{m}}\right) \\
& =\frac{\mu_{m}}{\sigma \psi^{1 / 2}}\left[\frac{\bar{f} \sigma}{\psi^{1 / 2}}\left(2+\frac{\sigma^{2}}{\gamma N(1-h)(c / M)}\right)\right]\left(\frac{\bar{p}_{i}-p_{i}}{p_{m}}\right),
\end{aligned}
$$

which gives the second equality in (30), using equation (28).

Proof of Proposition 4: The investors' aggregate weight in stock $i$ is

$$
\phi_{S, i}=(1-y) \phi_{m, i}+y \phi_{A, i}=(1-y) \phi_{m, i}+y\left(\phi_{m, i}+\phi_{i}\right)=\phi_{m, i}+y \phi_{i} .
$$

Substituting the last expression for $\phi_{S, i}$ into the market-clearing condition in equation (31) gives

$$
h \phi_{H, i}+(1-h)\left(\phi_{m, i}+y \phi_{i}\right)=\phi_{m, i}
$$

or

$$
h\left(\phi_{H, i}-\phi_{m, i}\right)=y(1-h) \phi_{i} .
$$

Then substituting the identities $\phi_{H, i}=\hat{p}_{i} /\left(N p_{m}\right)$ and $\phi_{m, i}=p_{i} /\left(N p_{m}\right)$ as well as the expression for $\phi_{i}$ in equation (30) gives

$$
\begin{aligned}
h\left(\frac{\hat{p}_{i}}{N p_{m}}-\frac{p_{i}}{N p_{m}}\right) & =y(1-h) \bar{f} \mu_{m}\left(\frac{1}{(c / M) \bar{f} y(1-h) N \psi}\right)^{1 / 2}\left(\frac{\bar{p}_{i}-p_{i}}{p_{m}}\right) \\
& =(1-h) \mu_{m}\left(\frac{\bar{f} y}{(c / M)(1-h) N \psi}\right)^{1 / 2}\left(\frac{\bar{p}_{i}-p_{i}}{p_{m}}\right) .
\end{aligned}
$$

Substituting for $\bar{f} y$ from equation (25) and simplifying gives

$$
\hat{p}_{i}-p_{i}=\frac{1-h}{h}\left(\frac{\gamma \mu_{m}}{\sigma^{2} / N+2 \gamma(1-h)(c / M)}\right)\left(\bar{p}_{i}-p_{i}\right),
$$

which directly yields equation (32) for $\theta$ as defined in equation (34).

Proof of Proposition 5: Let $\psi^{*}$ denote the mispricing measure defined in equation (14) that reflects the equililbrium prices that result when investors allocate $y^{*}$ to the optimal active portfolio. Observe that, since managers condition on prices, the relations in Proposition 1 hold with $\psi$ equal to $\psi^{*}$, and thus the optimal portfolio of active managers continues to be that with fund weights 
given by $\omega^{(j)}$ in equation (19), such that fee revenue is equal across managers. The aggregate active weight in stock $i$ in that portfolio is therefore given by equation (30) with $\psi$ equal to $\psi^{*}$ and $y$ equal to $y^{*}$ :

$$
\phi_{i}^{*}=\bar{f} \mu_{m}\left(\frac{1}{(c / M) \bar{f} y^{*}(1-h) N \psi^{*}}\right)^{1 / 2}\left(\frac{\bar{p}_{i}-p_{i}}{p_{m}}\right) .
$$

The optimal allocation to the above aggregate active portfolio is given by equation (25) with $\psi$ set to $\psi^{*}$, but instead the allocation $y^{*}$ is $\lambda$ times that optimal amount, resulting in

$$
\bar{f} y^{*}=\lambda \psi^{*} N(1-h)(c / M)\left(\frac{\gamma}{\sigma^{2}+2 \gamma N(1-h)(c / M)}\right)^{2} .
$$

The market-clearing condition as stated in equation (A22) becomes

$$
h\left(\phi_{H, i}-\phi_{m, i}\right)=y^{*}(1-h) \phi_{i}^{*} .
$$

As before when proceeding from equation (A22) to (A23), substituting into equation (A27) the identities for $\phi_{H, i}$ and $\phi_{m, i}$ as well as $\phi_{i}^{*}$ in equation (A25) gives

$$
h\left(\frac{\hat{p}_{i}}{N p_{m}}-\frac{p_{i}}{N p_{m}}\right)=(1-h) \mu_{m}\left(\frac{\bar{f} y^{*}}{(c / M)(1-h) N \psi^{*}}\right)^{1 / 2}\left(\frac{\bar{p}_{i}-p_{i}}{p_{m}}\right) .
$$

Substituting for $\bar{f} y^{*}$ from equation (A26) and simplifying then gives

$$
\hat{p}_{i}-p_{i}=\lambda^{1 / 2} \frac{1-h}{h}\left(\frac{\gamma \mu_{m}}{\sigma^{2} / N+2 \gamma(1-h)(c / M)}\right)\left(\bar{p}_{i}-p_{i}\right),
$$

which directly yields equation (32) with $\theta$ replaced by $\theta^{*}$ as defined in equation (36). The net alpha on the aggregate active portfolio is given by equation (A15) with $y$ and $\psi$ set to $y^{*}$ and $\psi^{*}$ :

$$
\alpha_{A}^{*}=\bar{f}\left[\left(\frac{\psi^{*}}{c \bar{f} y^{*}(1-h) N / M}\right)^{1 / 2}-2\right] .
$$

Substituting for $\bar{f} y^{*}$ from equation (A26) and simplifying gives

$$
\begin{aligned}
\alpha_{A}^{*} & =\bar{f}\left[\lambda^{-1 / 2}\left(\frac{\sigma^{2}+2 \gamma N(1-h)(c / M)}{\gamma N(1-h)(c / M)}\right)-2\right] \\
& =\lambda^{-1 / 2}\left(\frac{\bar{f} \sigma^{2}}{\gamma N(1-h)(c / M)}-2 \bar{f}\left(\lambda^{1 / 2}-1\right)\right),
\end{aligned}
$$

which is equivalent to equation (37), using equation (27). The market-adjusted variance of the aggregate active portfolio is given by equation (A17) with $y$ set to $y^{*}$ :

$$
\sigma_{A}^{* 2}=\frac{\sigma^{2} \bar{f}}{y^{*}(1-h) N(c / M)} .
$$


Substituting for $y^{*}$ from equation (A26) and simplifying gives

$$
\begin{aligned}
\sigma_{A}^{* 2} & =\frac{\bar{f}^{2} \sigma^{2}}{\lambda \psi^{*}}\left(\frac{\sigma^{2}+2 \gamma N(1-h)(c / M)}{\gamma N(1-h)(c / M)}\right)^{2} \\
& =\frac{\psi}{\lambda \psi^{*}}\left[\frac{\bar{f}^{2} \sigma^{2}}{\psi}\left(2+\frac{\sigma^{2}}{\gamma N(1-h)(c / M)}\right)^{2}\right]
\end{aligned}
$$

and taking square roots gives equation (38), using equation (28). The result for $I_{A}^{*}$ in equation (39) then follows directly from division of $\alpha_{A}^{*}$ by $\sigma_{A}^{*}$. 


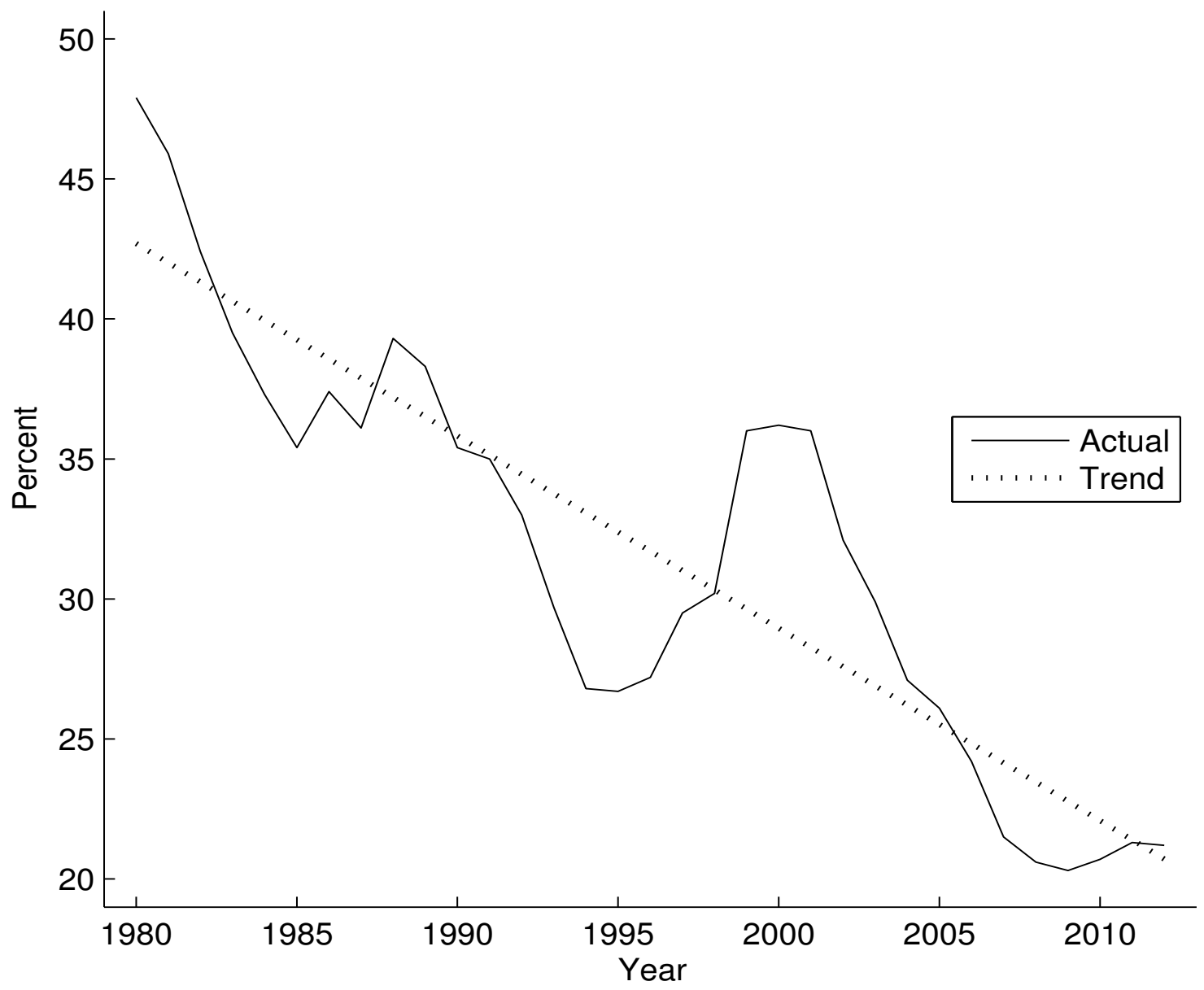

Figure 1. Individual Equity Ownership. The solid line plots annual values for the fraction of the US equity market that is owned directly by individuals. The dotted line plots a linear trend fit through the data points. 
A. Active Allocations

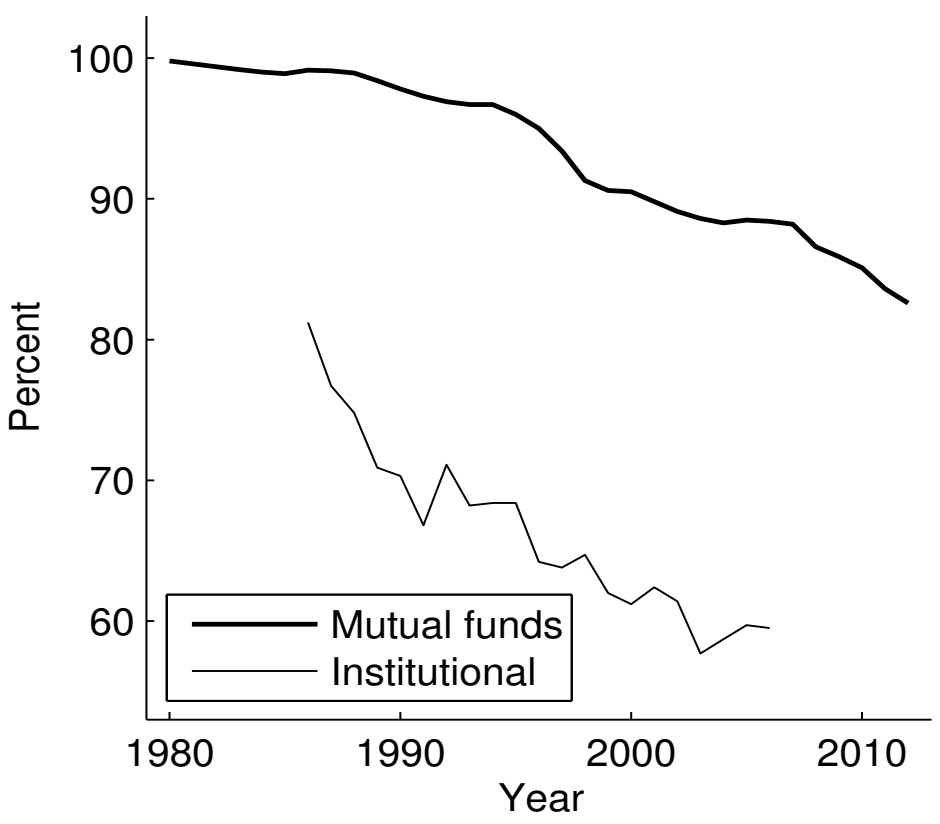

C. Mutual Fund Tracking Error

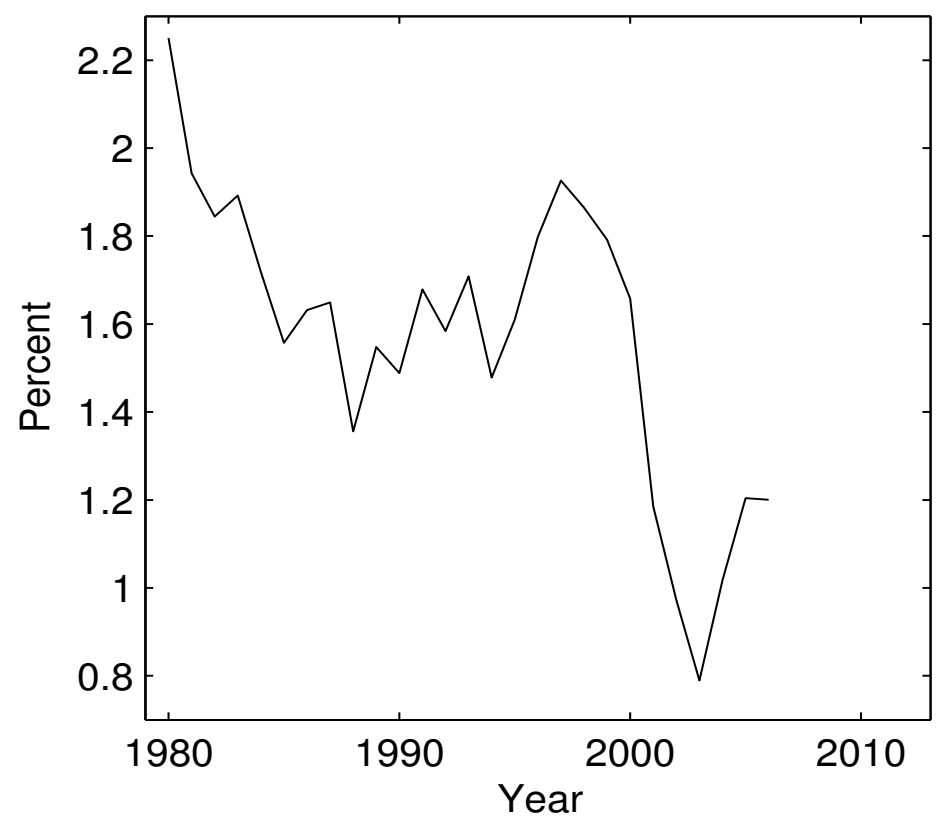

B. Active Fees
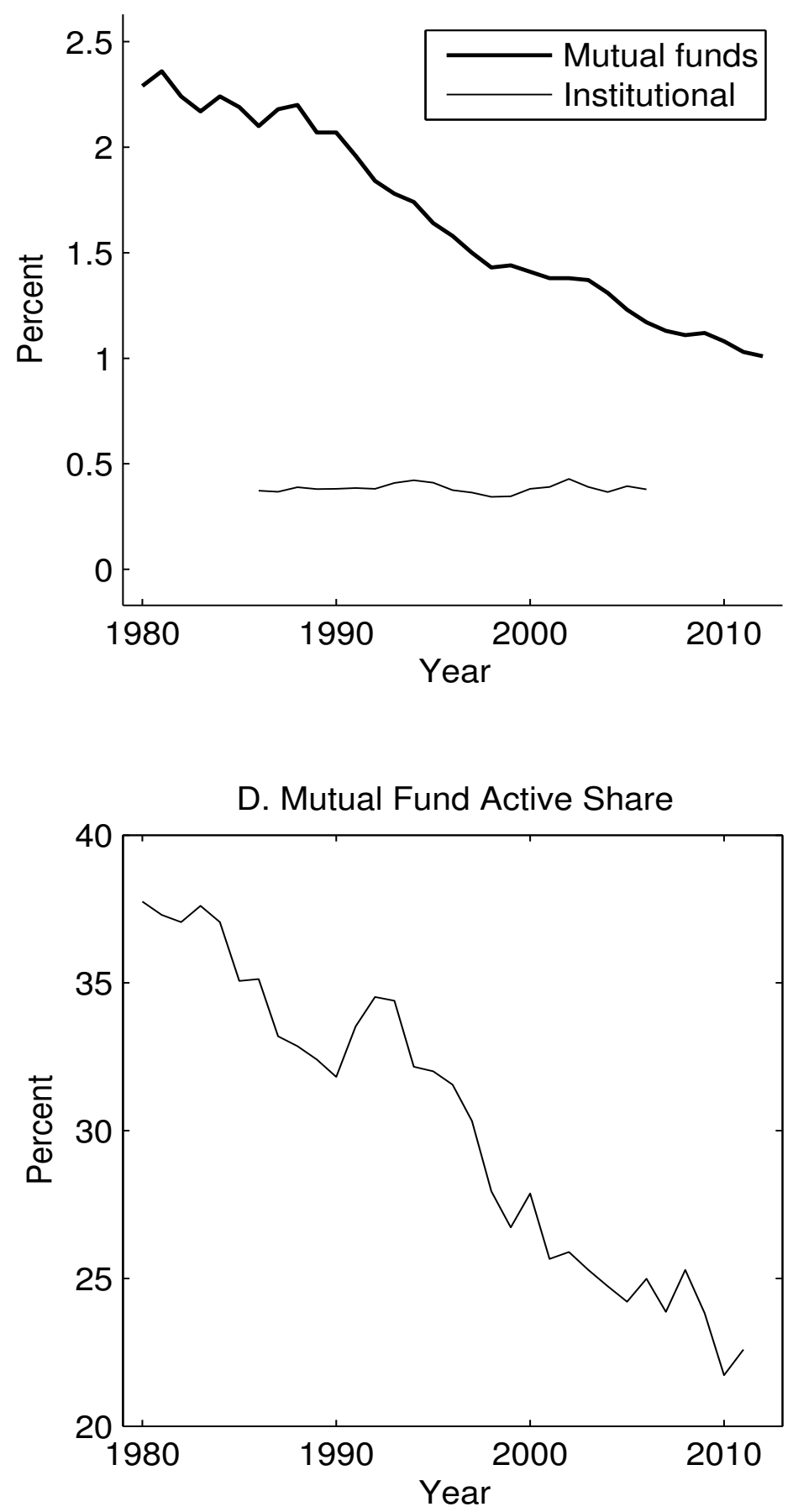

Figure 2. Trends in Active Management. Panel A plots the fraction of equity mutual fund assets that are actively managed (thicker line) and the fraction of institutionally owned equity that is actively managed (thinner line). Panel B plots the aggregate cost to investors of owning active equity mutual funds (thicker line) and the aggregate fee paid by institutional investors for active equity management. Panel $\mathrm{C}$ plots the estimated tracking error of the aggregate portfolio of active equity mutual funds. Panel D plots the estimated active share of that portfolio. 


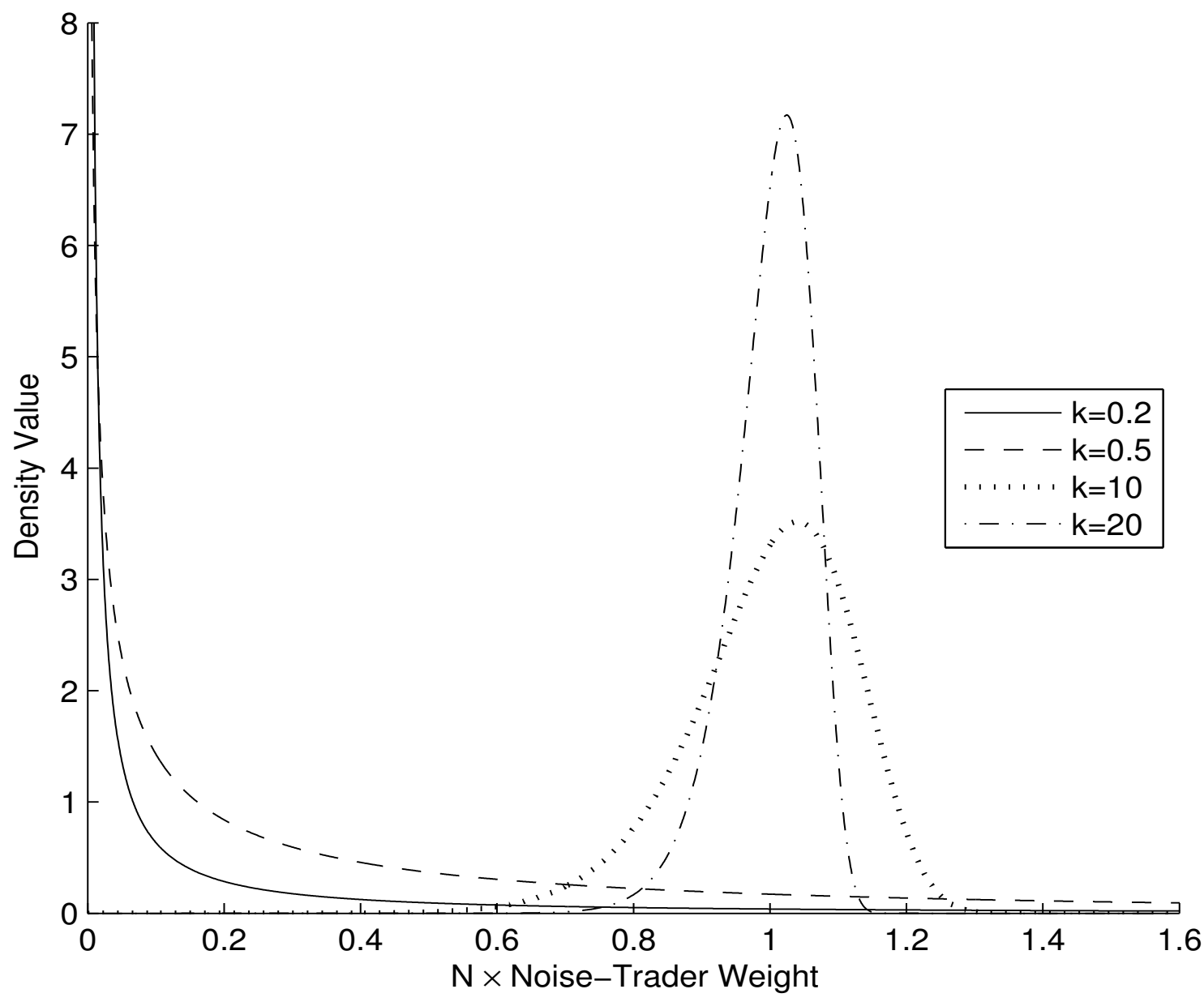

Figure 3. Noise Trading Densities. The figure plots alternative specifications of a Weibull density for approximating the cross-sectional distribution of $N \phi_{H, i}$, where $N$ is the number of stocks in the market and $\phi_{H, i}$ is the aggregate weight that noise traders place in stock $i$. All densities have 1.0 as the mean and differ with respect to the shape parameter $k$. 
A. Active Allocations

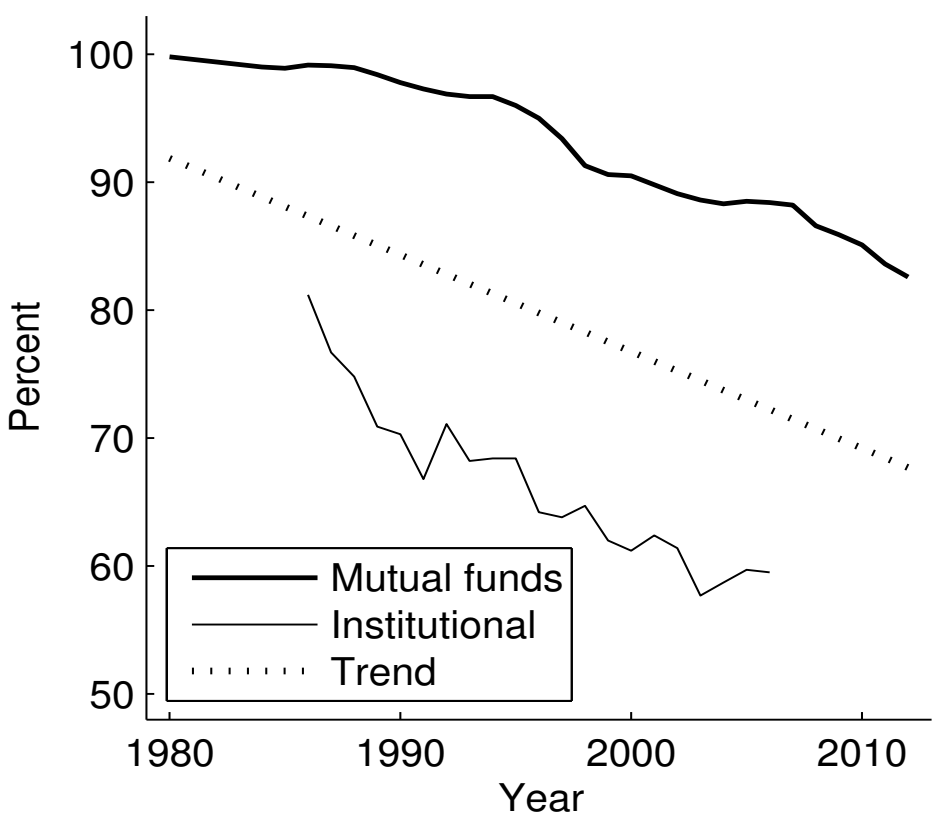

C. Tracking Error

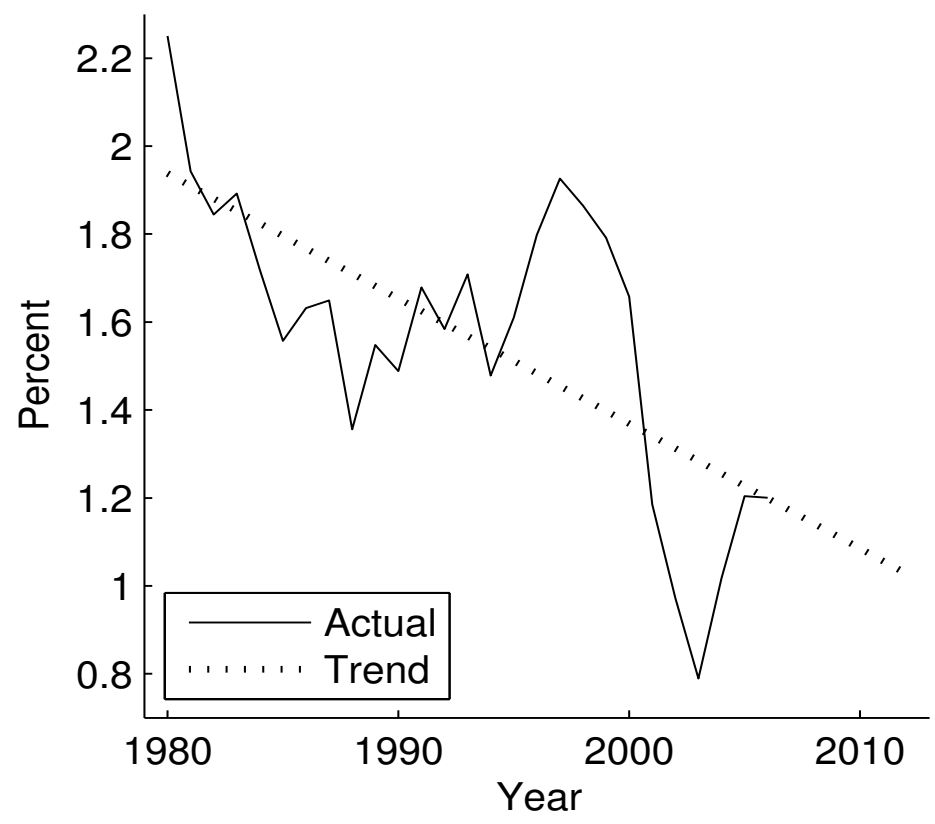

B. Active Fees
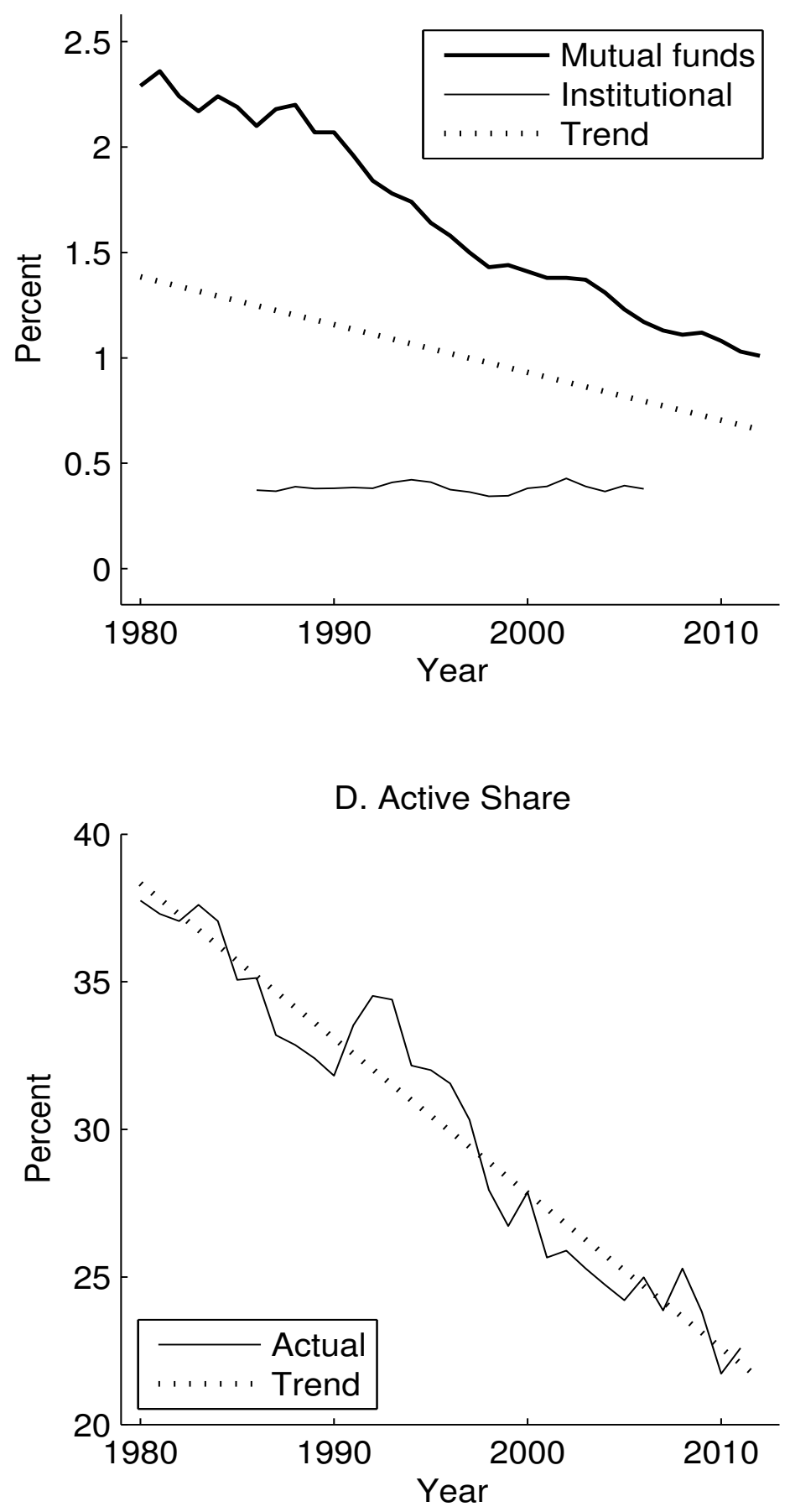

Figure 4. Fitted Investment Trends. Panels A through D display the data series plotted in Figure 2 (solid lines) as well as the fitted linear trends (dotted lines) used in the model calibration. In Panels A and B, the trend is constructed as the average of the linear trends fitted through the mutual-fund series (thicker lines) and the institutional series (thinner lines). 


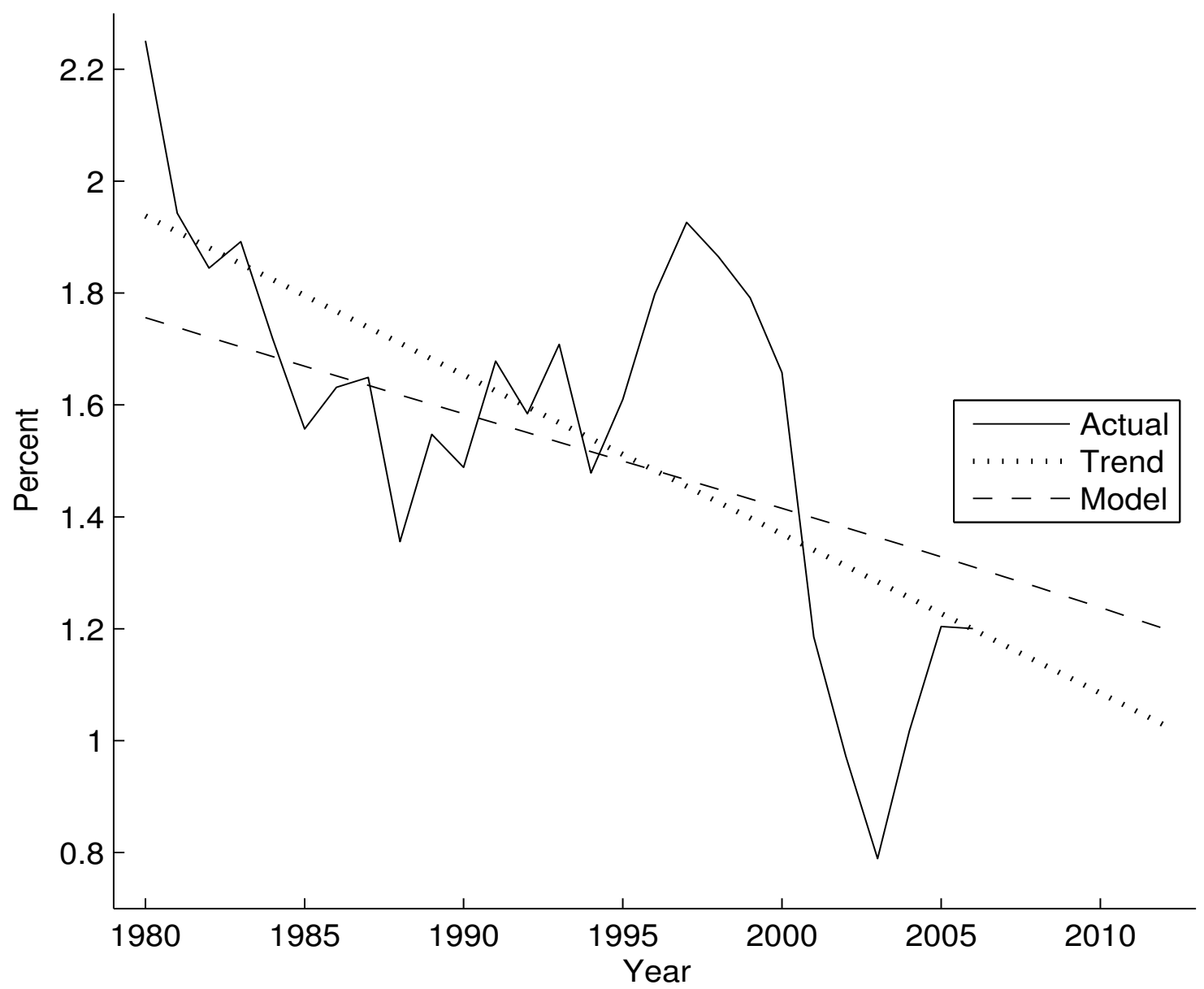

Figure 5. Active Management Tracking Error. The figure plots the estimated year-by-year tracking error for equity mutual funds (solid line), the linear trend fitted through those values (dotted line), and the implied model values for aggregate tracking error (dashed line). The model parameter governing trading costs is calibrated to the mid-sample 1996 trend level of tracking error. 


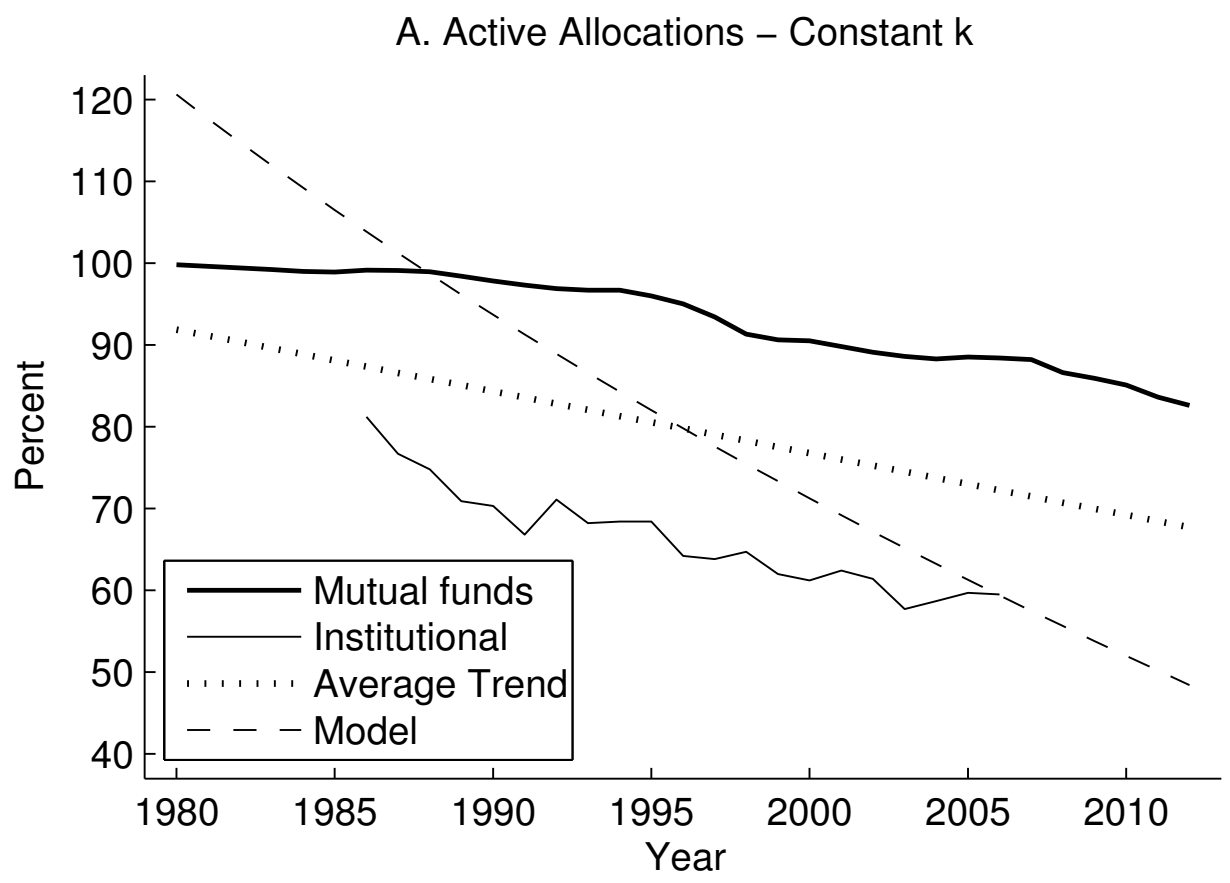

B. Active Allocations - Declining k

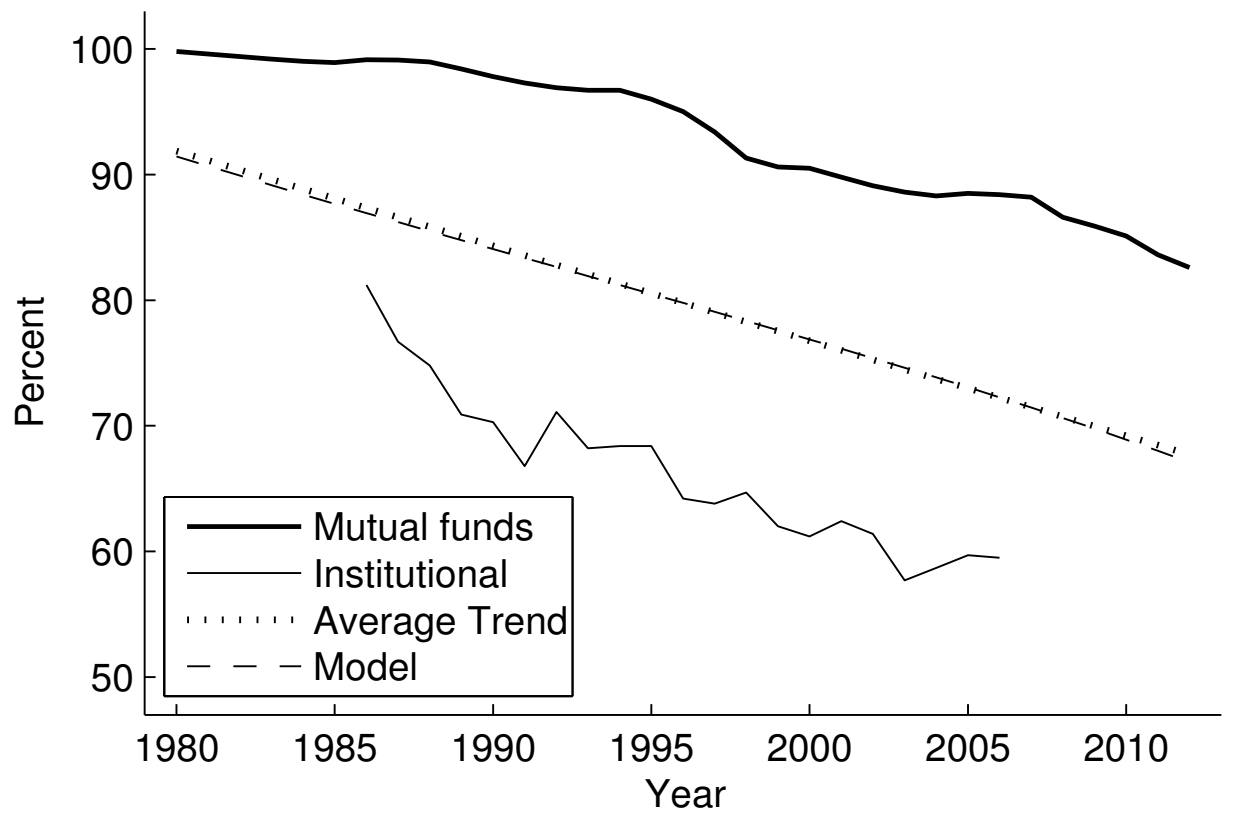

Figure 6. Allocation to Active Management. The figure plots the year-by-year fractions of equity under active management (solid lines), the trends based on that data (dotted lines), and the model implied values (dashed lines). In Panel A, the parameter $k$, which characterizes the distribution of noise-trader weights, is held constant at 0.215 , the value calibrated to the mid-sample 1996 level of the data trend. In panel B, the value of $k$ declines linearly from 0.228 in 1980 to 0.201 in 2012. 


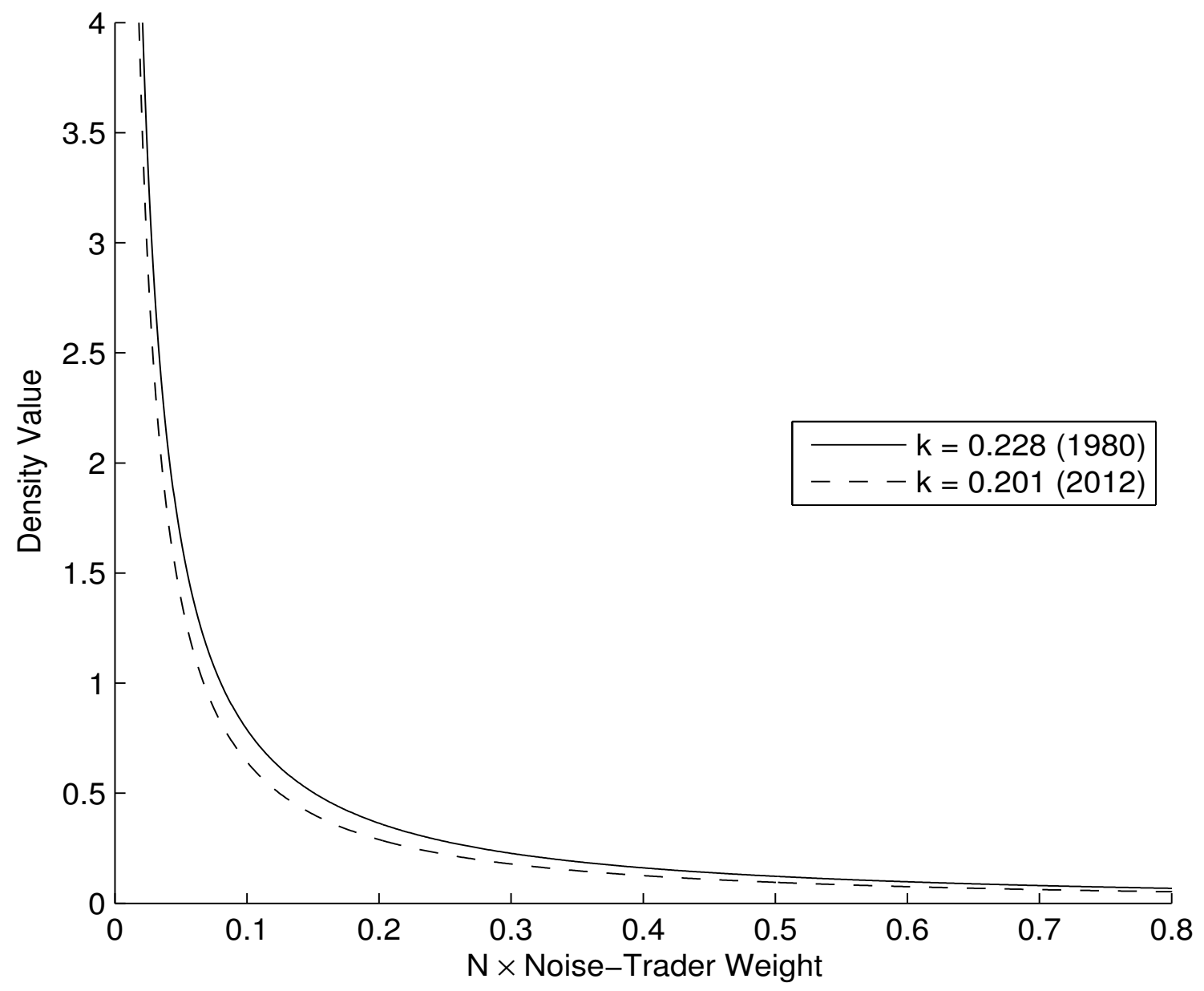

Figure 7. Shift in Noise Trading Densities. The figure plots the Weibull densities for $N \phi_{H, i}$ that correspond to the 1980 and 2012 values of the shape parameter $k$ that declines linearly when constructing Panel B of Figure 6. $N$ is the number of stocks in the market and $\phi_{H, i}$ is the aggregate weight that noise traders place in stock $i$. Both densities have 1.0 as the mean. 


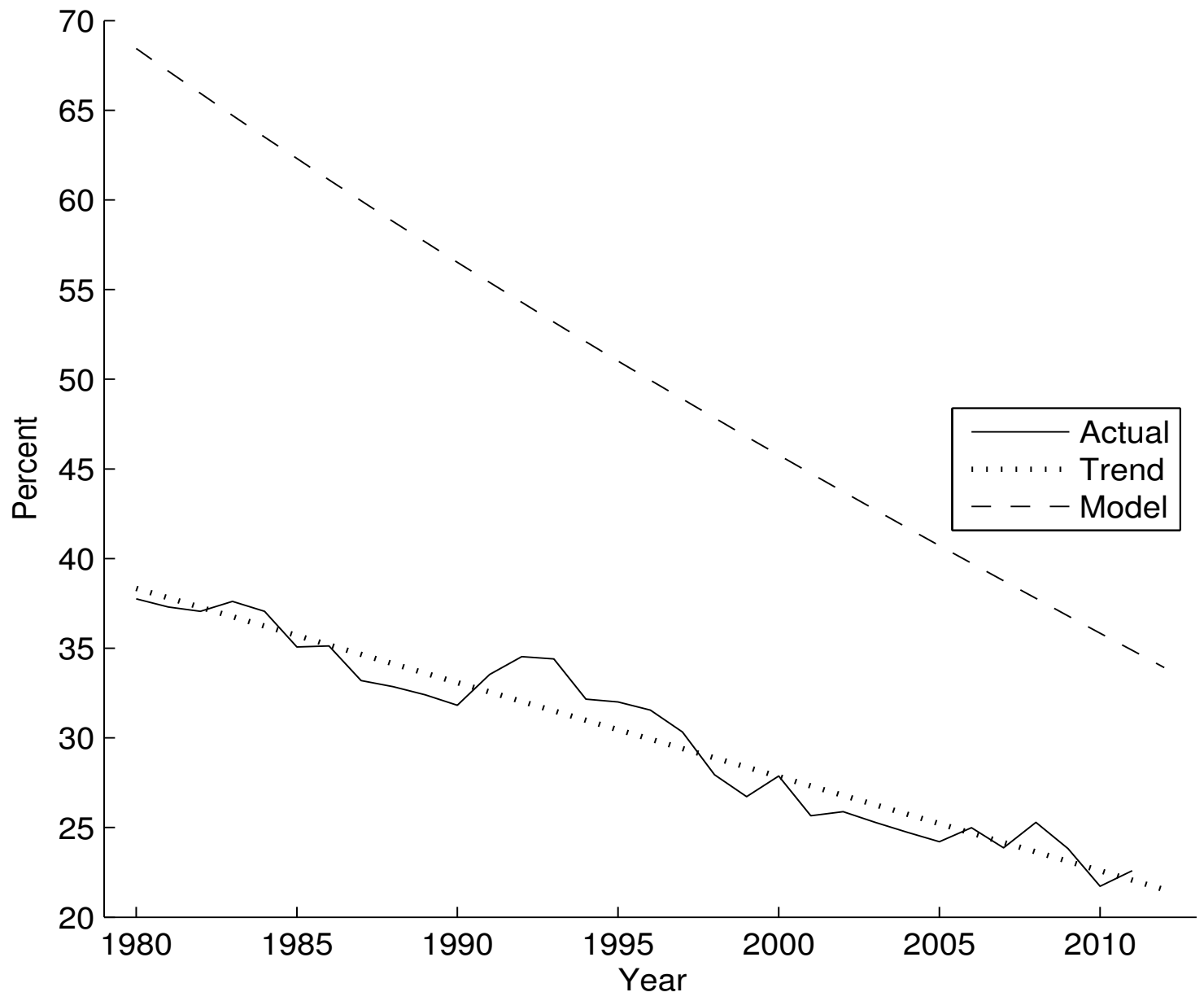

Figure 8. Active Share. The figure plots the year-by-year estimates of active share (solid line), the trend based on that data (dotted line), and the model implied values (dashed line). 


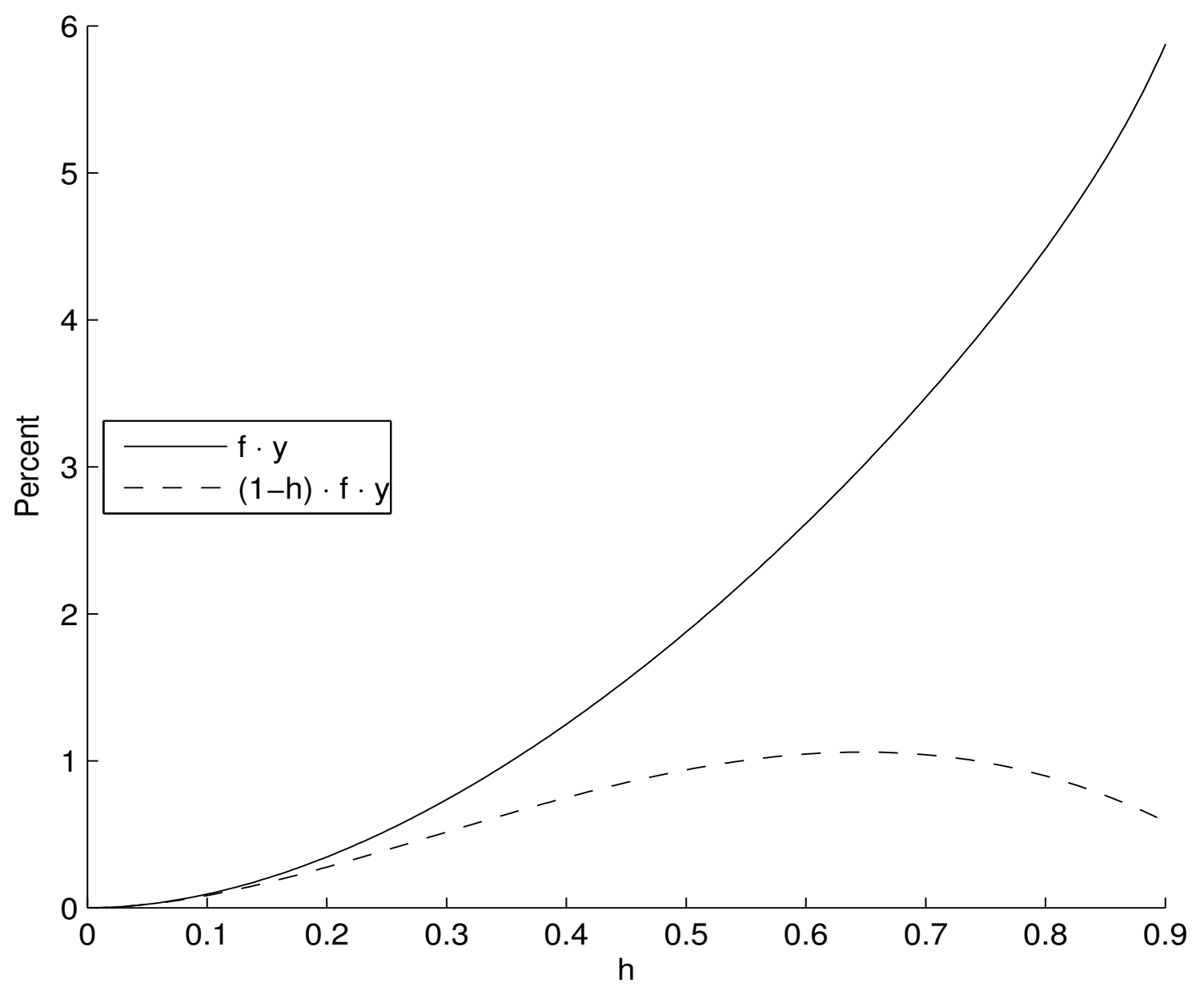

Figure 9. Noise Trading and Fee Revenue. The figure plots the model's implied relation between fee revenue and the fraction of the equity market owned by noise traders $(h)$. The solid line plots $\bar{f} y$, where $\bar{f}$ is the average fee rate and $y$ is the fraction of investors' stock-market wealth allocated to active management. The dashed line plots $(1-h) \bar{f} y$, which is fee revenue as a fraction of the total value of the stock market. 

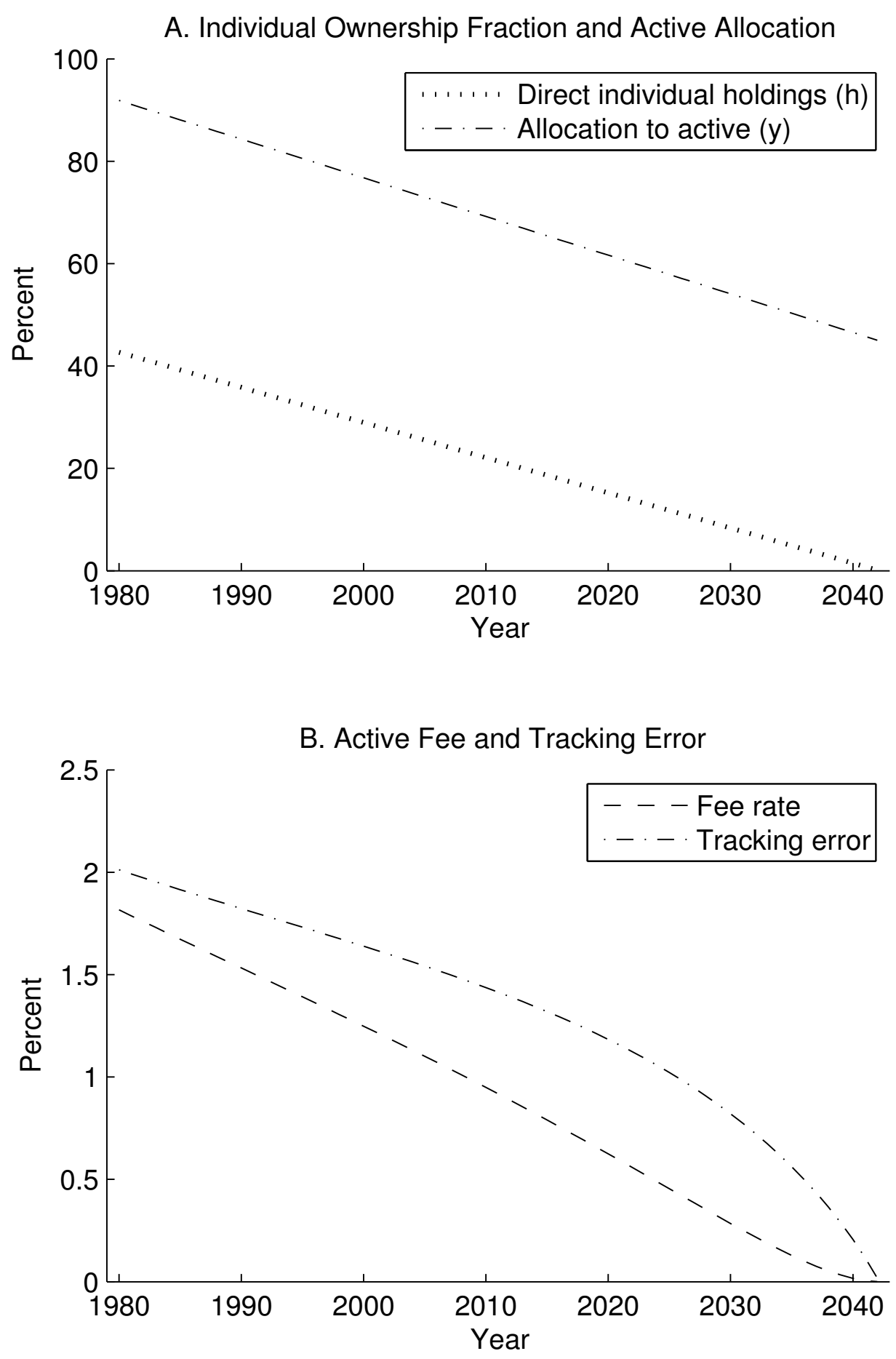

Figure 10. Future Investment Trends. The plots in Panel A extrapolate into future years the linear trends in Figures 1 and 4 in the fraction $(h)$ of the equity market owned by noise traders (dotted line) and the fraction $(y)$ investors allocate to active management (dash-dot line). Given those trends, Figure B plots the model's implied values for active management's fee rate (dashed line) and tracking error (dash-dot line). 


\section{References}

Barber, Brad M., Terrance Odean, and Ning Zhu, 2009, Systematic noise, Journal of Financial Markets 12, 547-569.

Barber, Brad M., and Terrance Odean, 2008, All that glitters: The effect of attention and news on the buying behavior of individual and institutional investors, Review of Financial Studies 21, $785-818$.

Berk, Jonathan B., and Richard C. Green, 2004, Mutual fund flows and performance in rational markets, Journal of Political Economy 112, 1269-1295.

Black, Fischer, 1986, Noise, Journal of Finance 41, 529-543.

Blume, Marshall E., Jean Crockett, and Irwin Friend, 1974, Stock ownership in the United States: Characteristics and trends, Survey of Current Business 54 (November), 16-40.

Blume, Marshall E., and Irwin Friend, 1975, The asset structure of individual portfolios and some implications for utility functions, Journal of Finance 30, 585-603.

Brandt, Michael W., Alon Brav, John R. Graham, and Alok Kumar, 2010, The idiosyncratic volatility puzzle: Time trend or speculative episodes, Review of Financial Studies 23, 864-899.

Chen, Joseph, Harrison Hong, Ming Huang, and Jeffrey Kubik, 2004, Does fund size erode mutual fund performance? American Economic Review, 94, 1276-1302.

Chordia, Tarun, Richard Roll, and Avanidhar Subrahmanyam, 2008, Liquidity and market efficiency, Journal of Financial Economics 87, 249-268.

Chordia, Tarun, Richard Roll, and Avanidhar Subrahmanyam, 2011, Recent trends in trading activity and market quality, Journal of Financial Economics 101, 243-263.

Chordia, Tarun, Avanidhar Subrahmanyam, and Qing Tong, 2013, Trends in the cross-section of expected stock returns, Working paper, Emory University, UCLA, and Singapore Management University.

Cremers, K.J. Martijn, and Antti Petajisto, 2009, How active is your fund manager? A new measure that predicts performance, Review of Financial Studies 22, 3329-3365.

Del Guercio, Diane, and Jonathan Reuter, 2013, Mutual fund performance and the incentive to generate alpha, forthcoming Journal of Finance.

De Long, J. Bradford, Andrei Shleifer, Lawrence H. Summers, and Robert J. Waldmann, 1990, Noise trader risk in financial markets, Journal of Political Economy 98, 703-738. 
Dorn, Daniel, Gur Huberman, and Paul Sengmueller, 2008, Correlated trading and returns, Journal of Finance 58, 885-920.

Edelen, Roger M., Richard Evans, and Gregory B. Kadlec, 2007, Scale effects in mutual fund performance: The role of trading costs, Working paper, Echo Investment Advisors, Boston College, and Virginia Tech.

Edelen, Roger, Richard Evans, and Gregory Kadlec, 2013, Shedding light on "invisible” costs: Trading costs and mutual fund performance, Financial Analysts Journal 69 (January/February), $33-44$.

Fama, Eugene F., and Kenneth R. French, 2010, Luck versus skill in the cross section of mutual fund returns, Journal of Finance 65, 1915-1947.

Fang, Lily, and Joel Peress, 2009, Media coverage and the cross-section of stock returns, Journal of Finance 64, 2023-2052.

Feng, Lei, and Mark S. Seasholes, 2004, Correlated trading and location, Journal of Finance 59, 2117-2144.

Ferreira, Miguel A., Aneel Keswani, António F. Miguel, and Sofia Ramos, 2013, The determinants of mutual fund performance: A cross-country study, Review of Finance 17, 483-525.

Ferreira, Miguel A., Aneel Keswani, António F. Miguel, and Sofia Ramos, 2013b, Testing the Berk and Green model around the world, Working paper, Nova School of Business and Economics.

French, Kenneth R., 2008, The cost of active investing, Journal of Finance 63, 1537-1573.

Garcia, Diego, and Joel M. Vanden, 2009, Information acquisition and mutual funds, Journal of Economic Theory 144, 1965-1995.

Glode, Vincent, 2011, Why mutual funds “underperform," Journal of Financial Economics 99, 546-559.

Goetzmann, William N., and Alok Kumar, 2008, Equity portfolio diversification, Review of Finance $12,433-463$.

Gruber, Martin J., 1996, Another puzzle: The growth in actively managed mutual funds, Journal of Finance 51, 783-810.

Hugonnier, Julien, and Ron Kaniel, 2010, Mutual fund portfolio choice in the presence of dynamic flows, Mathematical Finance 20, 187-227.

Jensen, Michael C., 1968, The performance of mutual funds in the period 1945-1964, Journal of Finance 23, 389-416. 
Johnson, Normal L., and Samuel Kotz, 1970, Continuous Univariate Distributions - 1 (John Wiley \& Sons, New York, NY).

Kacperczyk, Marcin, Stijn Van Nieuwerburgh, and Laura Veldkamp, 2013a, Time-varying fund manager skill, Journal of Finance, forthcoming.

Kacperczyk, Marcin, Stijn Van Nieuwerburgh, and Laura Veldkamp, 2013b, Rational attention allocation over the business cycle, Working paper, New York University.

Kelly, Morgan, 1995, All their eggs in one basket: Portfolio diversification of US households, Journal of Economic Behavior and Organization 27, 87-96.

Kosowski Robert, 2011, Do mutual funds perform when it matters most to investors? US mutual fund performance and risk in recessions and expansions, Quarterly Journal of Finance 1, 607664.

Kyle, Albert S., 1985, Continuous auctions and insider trading, Econometrica 53, 1315-1335.

Kyle, Albert S., and Anna A. Obizhaeva, 2013, Market microstructure invariance: Theory and empirical tests, Working paper, University of Maryland.

Lease, Ronald C., Wilbur G. Lewellen, and Gary G. Schlarbaum, 1974, The individual investor: Attributes and attitudes, Journal of Finance 29, 413-433.

Malkiel, Burton G., 1995, Returns from investing in equity mutual funds 1971 to 1991, Journal of Finance 50, 549-572.

Merton, Robert C., 1987, A simple model of capital market equilibrium with incomplete information, Journal of Finance 42, 483-510.

Pástor, Ľuboš, and Robert F. Stambaugh, 2002, Mutual fund performance and seemingly unrelated assets, Journal of Financial Economics 63, 315-349.

Pástor, Ľuboš, and Robert F. Stambaugh, 2012, On the size of the active management industry, Journal of Political Economy 120, 740-781.

Pástor, Ľuboš, Robert F. Stambaugh, and Lucian A. Taylor, 2013, Scale and skill in active management, Working paper, University of Chicago and University of Pennsylvania.

Petajisto, Antti, 2009, Why do demand curves for stocks slope down?, Journal of Financial and Quantitiative Analysis 44, 10131044.

Polkovnichenko, Valery, 2005, Household portfolio diversification: A case for rank-dependent preferences, Review of Financial Studies 18, 1467-1502. 
Pollet, Joshua, and Mungo Wilson, 2008, How does size affect mutual fund behavior? Journal of Finance 63, 2941-2969.

Reuter, Jonathan, and Eric Zitzewitz, 2013, How much does size erode mutual fund performance? A regression discontinuity approach, Working paper, Boston College.

Ross, Stephen A., 1976, The arbitrage theory of capital asset pricing, Journal of Economic Theory $13,341-360$.

Rydqvist, Kristian, Joshua Spizman, and Ilya Strebulaev, 2014, Government policy and ownership of equity securities, Journal of Financial Economics 111, 70-85.

Sharpe, William F. 1991, The arithmetic of active management, Financial Analysts Journal 47 (January/February), 7-9.

Shiller, Robert J, 2000, Irrational Exuberance (Princeton University Press, Princeton, NJ).

Shleifer, Andrei, and Lawrence H. Summers, 1990, The noise trader approach to finance, Journal of Economic Perspectives 4, 19-33.

Stambaugh, Robert F., Jianfeng Yu, and Yu Yuan, 2013, Arbitrage asymmetry and the idiosyncratic volatility puzzle, Working paper, University of Pennsylvania, University of Minnesota, and Shanghai Advanced Institute of Finance.

Treynor, Jack L., and Fischer Black, 1973, How to use security analysis to improve portfolio selection, Journal of Business 46, 66-86.

Wermers, Russ, 2000, Mutual fund performance: An empirical decomposition into stock-picking talent, style, transactions costs, and expenses.” Journal of Finance 55, 1655-1695.

Yan, Xuemin, 2008, Liquidity, investment style, and the relation between fund size and fund performance, Journal of Financial and Quantitative Analysis 43, 741-768. 


\section{Footnotes}

${ }^{1}$ See Black (1986, p. 531). Kyle (1985) also advances the concept of noise traders, whom Kyle models as random in their trading.

${ }^{2}$ French reports estimates through 2007. I extend his series through 2012 by taking $b$ times the fraction of equity held by households (including nonprofits) reported by the Federal Reserve, where $b$ is the ratio of French's 2007 value to the Fed's 2007 value.

${ }^{3}$ The mutual fund series in Panels A and B are supplied by the Investment Company Institute. Both institutional series are constructed with estimates reported by French (2008), who uses data from Greenwich Associates. That firm informs me that they recently adopted the policy that their data not be made available (by them or their clients) for academic research.

${ }^{4}$ I am grateful to Martijn Cremers for supplying this active share series, computed with respect to the Russell 1000 market benchmark. The plot displays within-year averages of quarterly values.

${ }^{5}$ In this interpretation, the trading cost is not viewed as a manager-specific price impact, such that if many other managers independently produce similar price impacts, the sum of such impacts aggregates to an implausibly large total price effect. Instead, one might imagine many intermediaries accessing different sources of liquidity or acting at slightly different times.

${ }^{6}$ Additional empirical studies include Chen et al. (2004), Pollet and Wilson (2008), Yan (2008), Ferreira et al. (2013a,b), and Reuter and Zitzewitz (2013).

${ }^{7}$ Hugonnier and Kaniel (2010) obtain a similar result for an active manager who dynamically allocates to equities and a riskless asset, although when the manager invests only in equities (as here), the fee irrelevance no longer obtains. Berk and Green (2004) also present a setting in which the manager's fee revenue is invariant to the fee rate.

${ }^{8}$ It is straightforward to verify that right-hand side of equation (34) has a positive derivative with respect to $h$.

${ }^{9}$ Other studies reporting evidence of the poor diversification of individual portfolios include Kelly (1995) and Goetzmann and Kumar (2008).

${ }^{10}$ As Merton (1987) discusses, such constraints need not reflect behavioral bias and can be modeled in a rational setting.

${ }^{11}$ For a discussion of the Weibull distribution, see for example Johnson and Kotz (1970, chapter 20).

${ }^{12}$ A complimentary literature analyzes how cyclical fluctuations bear on active management. See, for example, Glode (2011), Kosowski (2011), and Kacperczyk, Van Nieuwerburgh, and Veldkamp (2013a, 2013b). 
${ }^{13}$ Also playing a role in maintaining the overall cost were the relatively high fees of hedge funds, whose share of the equity market grew to about $2.2 \%$ by 2007 , according to French's estimates. Hedge funds represent an additional segment of equity ownership, in addition to mutual funds and institutional portfolios, that I do not include here.

${ }^{14}$ Studies reporting negative average fund alphas include Jensen (1968), Malkiel (1995), Gruber (1996), Wermers (2000), Pástor and Stambaugh (2002), Fama and French (2010), and Del Guercio and Reuter (2013). 